\title{
A Field Study of How Wind Waves and Currents May Contribute to the Deterioration of Saltmarsh Fringe
}

\author{
Arash Karimpour $^{1}$ • Qin Chen ${ }^{2}$ - Robert R. Twilley ${ }^{3}$
}

Received: 26 March 2015 /Revised: 12 October 2015 / Accepted: 28 October 2015 /Published online: 13 November 2015

(C) The Author(s) 2015. This article is published with open access at Springerlink.com

\begin{abstract}
Deltaic landscapes, such as the Mississippi River Delta, are sites of extensive conversion of wetlands to open water, where increased fetch may contribute to erosion of marsh edges, increasing wetland loss. A field experiment conducted during a storm passage tested this process through the observations of wave orbital and current velocities in the fringe zone of a deteriorating saltmarsh in Terrebonne Bay, Louisiana. Incident waves seaward of the marsh edge and wave orbital and current velocities immediate landward of the marsh edge were measured. Through a dimensional analysis, it shows that the current and orbital velocities in the marsh fringe were controlled by the incident waves, inundation depth, submergence ratio, and vegetation density. Similarly, it is shown that the longshore currents in the inundated saltmarsh fringe depended on the local wave-induced momentum flux, vegetation submergence, and vegetation density in the fringe zone. The cross-shore current showed the presence of a return flow in the lower region of the velocity profile. A high correlation between the current direction and the local flow-wave energy ratio as well as the vegetation submergence and density is found, indicating the important
\end{abstract}

Communicated by David Keith Ralston

Qin Chen

qchen@1su.edu

1 Louisiana Sea Grant, Louisiana State University, Baton Rouge, LA, USA

2 Department of Civil and Environmental Engineering, Center for Computation and Technology, and Coastal Studies Institute, Louisiana State University, Baton Rouge, LA, USA

3 Department of Oceanography and Coastal Sciences, Louisiana Sea Grant, and Coastal Studies Institute, Louisiana State University, Baton Rouge, LA, USA role of surface waves in the fringe flow landward of an inundated wetland under storm conditions. The field observations shed light on the potential ecological consequences of increased wave activities in coastal saltmarsh wetlands owing to subsidence, sea level rise, limited sediment supply, increases in wind fetch, and storm intensity.

Keywords Saltmarsh wetland · Wave-induced current - Wave orbital velocity $\cdot$ Vegetated flow $\cdot$ Wetland erosion

\section{Introduction}

Coastal wetlands provide important benefits known as ecosystem services such as improving water quality, trapping sediments, reducing shoreline erosion rates, providing habitat for estuarine species, and contributing to the local economy through fishing and tourism industries (e.g., Gulf Restoration Network 2004; Barrett-O'Leary 2011; Louisiana Coastal Protection and Restoration Authority (CPRA) 2012). Another important ecosystem service is protecting coastal areas from storm impacts, as suggested by an estimate that wetlands provide US\$23.2 billion per year in storm protection services in the USA (Costanza et al. 2008). Storm surge attenuation by wetlands depends on the extent of wetland area surrounding a coastal landscape, storm strength (e.g., Wamsley et al. 2010; Hu et al. 2015), and biomechanical properties of wetland vegetation (e.g., Zhao and Chen 2014; Lapetina and Sheng 2014).

All of these benefits are at risk due to the substantial degradation of wetlands along coastal landscapes. The northern Gulf of Mexico, which is among the largest coastal wetland areas in the conterminous USA (Stedman and Dahl 2008), lost about half of its wetlands from 1780 to 1980 (Dahl 1990). Louisiana alone accounts for $80-90 \%$ of the coastal wetland losses in the 
USA (Tibbetts 2006; Couvillion et al. 2011). The average land loss in Louisiana during 1985 to 2010 was about $42.9 \mathrm{~km}^{2} /$ year (Couvillion et al. 2011). A total of $4869 \mathrm{~km}^{2}$ of wetlands have been converted to open water since 1930 in Louisiana, which is projected to lose another $4532 \mathrm{~km}^{2}$ by 2060 under current conditions (Louisiana Coastal Protection and Restoration Authority (CPRA) 2012). Much of this coastal wetland loss is attributed to submergence, given that reduced sediment supply limits the increase in marsh elevation relative to increase in water levels due to sea level rise and subsidence, causing the marsh surface to drown (Boesch et al. 1994; and others).

An increased fetch as a result of wetlands converting to open water over the last century has produced higher wind waves breaking on the marsh edge (e.g., Tonelli et al. 2010; Prahalad et al. 2014) causing considerable erosion of wetlands (Mariotti and Fagherazzi 2010; Mariotti et al. 2010; Marani et al. 2011; Fagherazzi et al. 2013; McLoughlin et al. 2014). This process of wetland loss has been less well documented in deltaic landscapes where large extensive wetland landscapes have been slowly replaced by shallow bays and estuaries. A majority of the studies on wetland edge erosion focused on the direct impact of waves on the marsh perimeter, and less research has been undertaken on the hydrodynamics of waveinduced flows on the surface of coastal wetlands. The wave power when water levels exceed the marsh platform was considered non-destructive to the marsh edge (e.g. McLoughlin et al. 2014). Although flows through vegetation have been studied extensively both in open channels and adjacent wetlands (e.g., Folkard 2011; Montakhab et al. 2012; Nepf 2012a, b), a majority of studies were focused on unidirectional flows through freshwater vegetation. Even though, recently, more attention has been paid to oscillatory flows in coastal vegetated areas, where both waves and currents coexist (e.g., Luhar et al. 2010; Callaghan et al. 2010; Manca et al. 2012), most of the existing studies focused on wave energy dissipation caused by vegetation (e.g., Paul and Amos 2011; Chen and Zhao 2012; Jadhav et al. 2013; Jadhav and Chen 2013; Ozeren et al. 2013; Anderson and Smith 2014; Blackmar et al. 2014; Möller et al. 2014). By contrast, there are few studies on the wave-induced currents on the surface of coastal wetlands, especially under storm and field conditions (e.g., Lacy and Hoover 2011; Truong et al. 2014). We propose that understanding the hydrodynamics of waves and currents within saltmarsh vegetation is necessary to identify how these flows may contribute to wetland loss.

Flow hydrodynamics in the fringe zone of a saltmarsh, also referred to as high marsh zone, were investigated using field experiments conducted in Terrebonne Bay, Louisiana, during the passage of a cold front, a frequent weather system on the northern Gulf of Mexico between late fall and early spring. The main research goal was to investigate currents and waves in the fringe zone of a saltmarsh as a function of the waves, inundation depth, and vegetation properties. The remainder of this paper is organized as follows. The study area and experimental methods are described first, followed by the data analysis method. Next, the correlations of the velocities in the saltmarsh fringe with incident and local waves, submergence ratio, and vegetation properties are presented, followed by discussion on the current direction in the saltmarsh fringe. Then, the ecological implications of waves and currents in the marsh fringe are discussed. The closing section provides a summary and conclusions of the study.

\section{Study Area and Methods}

\section{Study Area}

The study site is located in the upper Terrebonne Bay, Louisiana, on the north coast of the Gulf of Mexico (Fig. 1). Around 3000 to 4000 years ago Terrebonne Bay was a deltaic plain of the Mississippi River and, during the last 1000 years, was one of its main distributaries (Wang et al. 1993). The Terrebonne Bay estuary is surrounded by wetlands except to the south where it is connected to the Gulf of Mexico. During the advance of a passing cold front, southerly winds can increase water levels in the bay and cause the inundation of the surrounding wetlands. The deployment site, located at $29^{\circ} 12^{\prime}$ $35.00^{\prime \prime} \mathrm{N}$ and $90^{\circ} 34^{\prime} 12.58^{\prime \prime} \mathrm{W}$, represents a vanishing saltmarsh wetland with a relatively low elevation, allowing significant water inundation during a cold front passage. The field experiment was conducted from April 12-20, 2012. Strong southerly winds with relatively high wave activities were observed during that period, particularly from April 14-16, 2012.

A bottom-mounted pressure transducer (Ocean Sensor Systems, OSSI-010-003C, $\pm 0.05 \%$ accuracy) was deployed $47 \mathrm{~m}$ seaward of the marsh edge to measure the incident waves continuously at a sampling frequency of $10 \mathrm{~Hz}$. Four staff wave gauges (Ocean Sensor Systems, OSSI-010-004E, $\pm 1 \%$ accuracy) were deployed on the surface of the saltmarsh along a $3-\mathrm{m}$ transect in the fringe zone perpendicular to the shore to measure water levels and waves. The sensor array extended from the shoreline and at 1, 2, and $3 \mathrm{~m}$ landward in the fringe zone from the shoreline. The staff wave gauges were installed on 5.5 -m-long slotted angle steel bars, penetrated about $3.5 \mathrm{~m}$ into the marsh soil (Fig. 2.). The third staff wave gauge ( $2 \mathrm{~m}$ from shoreline) failed to record any data during the deployment, and will not be discussed further. The staff wave gauges sampled water levels for $20 \mathrm{~min}$ in every $30 \mathrm{~min}$ with a $10-\mathrm{Hz}$ sampling frequency.

To measure the flow velocity and wave energy on the marsh surface in the fringe zone, two acoustic Doppler velocimeters (ADVs) were deployed near the edge of the marsh inside the fringe zone. The first ADV (SonTek Triton ADV, $\pm 1 \%$ accuracy) with a 4 -Hz sampling frequency was located $1 \mathrm{~m}$ inland and the second ADV (SonTek 10-MHz ADV, 1\% 
Fig. 1 Study area located in Terrebonne Bay, Louisiana, on the north coast of the Gulf of Mexico. a Gulf of Mexico. b Terrebonne Bay. c Study site. (Map extracted from ArcGIS Explorer)

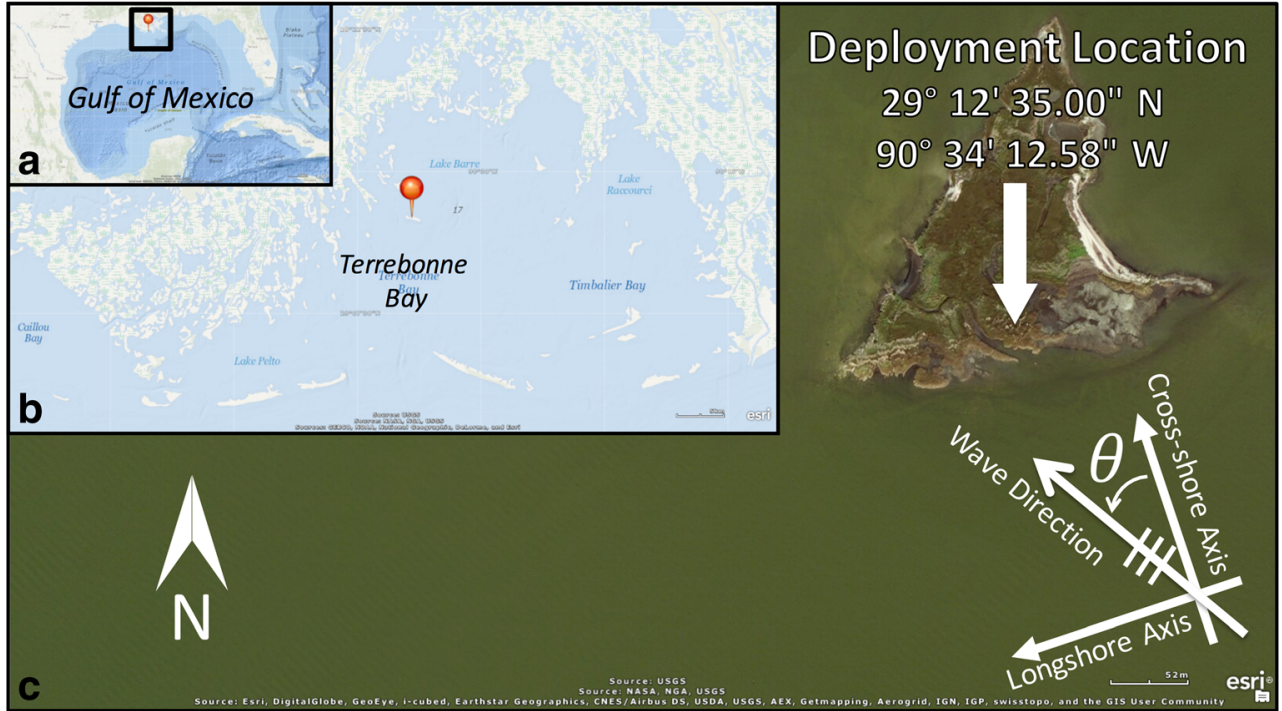

accuracy) with a $25-\mathrm{Hz}$ sampling frequency was located $2 \mathrm{~m}$ inland from the shoreline. To guarantee the stability and survival of the ADVs against the impact forces of the storm waves, a new deployment strategy was developed. First, the vegetation in a $0.1 \mathrm{~m} \times 0.1 \mathrm{~m}$ area was cut and removed at each ADV location to prevent the vegetation from interfering and disturbing the ADV reading. Then, two vertical holes were excavated in the saltmarsh. Care was taken to minimize damage to the surrounding vegetation during the installation. To prevent the ADVs from sinking, a foundation support was provided at the bottom of each hole by inserting two $2.5 \mathrm{~cm} \times 10 \mathrm{~cm} \times 1.5 \mathrm{~m}$ lumbers vertically into the marsh bed. The ADVs were wrapped in a $10-\mathrm{cm}$ diameter PVC pipe, and buried into the holes while secured by the underneath lumbers from vertical sinking. The ADVs were setup in an up-looking reading mode, recording a 1024-s burst in every $30 \mathrm{~min}$. Sampling points for both ADVs were located $14 \mathrm{~cm}$ above the bed (Figs. 2 and 3). Schematic drawings of the instruments and ADVs installation are shown in Fig. 3. Hereinafter, the instrument locations are denoted as, cross section (i) or $\mathrm{CS}_{\mathrm{i}}$ : for incident waves at $47 \mathrm{~m}$ seaward of the marsh edge; cross section 1 or $\mathrm{CS}_{1}$ : at the shoreline; cross sections $2\left(\mathrm{CS}_{2}\right), 3\left(\mathrm{CS}_{3}\right)$, and $4\left(\mathrm{CS}_{4}\right): 1,2$, and $3 \mathrm{~m}$ inland from the shoreline, respectively.

The saltmarsh deployment site was dominated by Spartina alterniflora during the experiments. The saltmarsh surface had a positive slope of 0.046 from the marsh edge landward. Properties of vegetation were sampled in three randomly selected quadrats of $0.5 \mathrm{~m} \times 0.5 \mathrm{~m}$, located around the deployment site. Live stems within each quadrat were counted, then cut at the soil surface level and brought back to the laboratory for further evaluation (Table 1 and Fig. 4).

Considering the spacing between plants as $\Delta x$ and $\Delta y$ in the $x$ and $y$ direction, respectively, the stem density which refers to the total number of plants per unit area is defined as $N_{v}=$ $\frac{\text { (Unit Area) } /(\Delta x \Delta y)}{\text { (Unit Area) }}$ or $N_{v}=1 /(\Delta x \Delta y)$. If the plants are homogeneously distributed, then $N_{v}=1 / \Delta s^{2}$, where $\Delta s=\Delta x=\Delta y$. The dimensionless vegetation density, which is proportional to the vegetated portion of the unit area, is defined by $N_{v} \times d_{v}^{2}$,
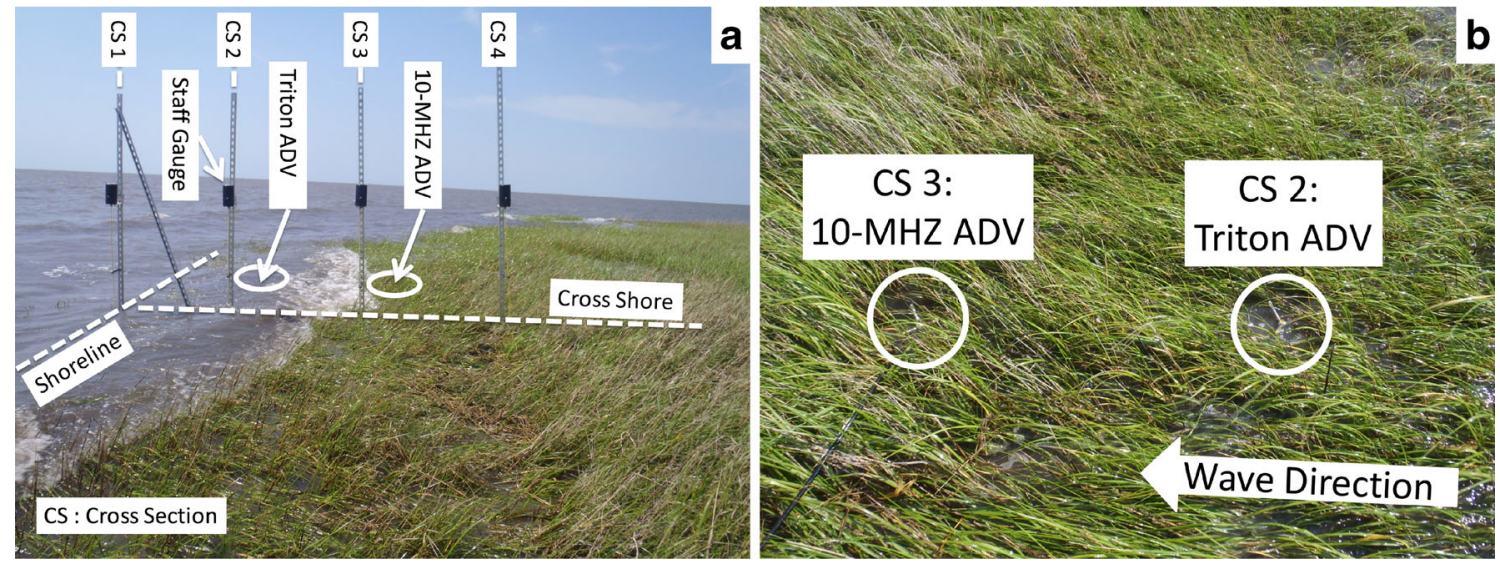

Fig. 2 Instrumentation in the marsh fringe. a Deployment plan. b ADVs before being inundated 
a

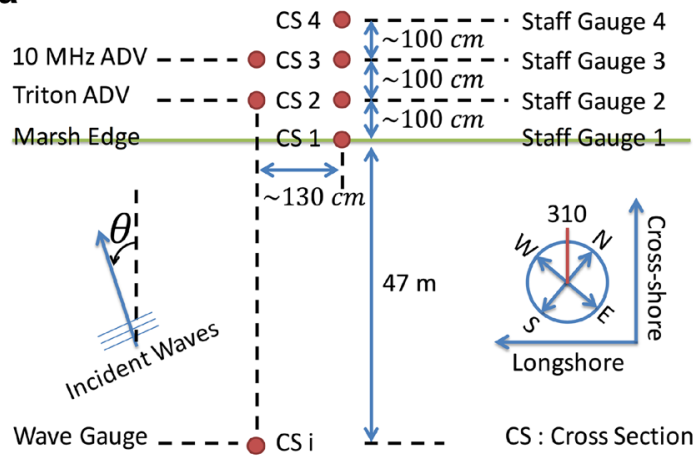

b

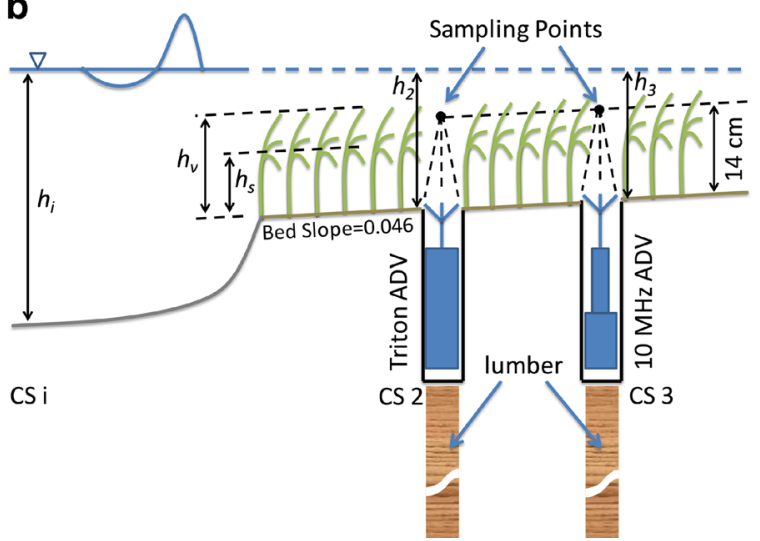

Fig. 3 Schematics of experimental design and instrument setup (not scaled). Left All instruments. Right ADVs

where $d_{v}$ is the vegetation stem diameter. At the study site the mean value of $N_{v} \times d_{v}^{2}$ was equal to 0.0114 .

To define how dense the vegetation was at the study site, the dimensionless relative density of the vegetation is calculated (Belcher et al. 2003). The relative density is defined by $a_{v} h_{v}$, where $a_{v}$ is the vegetation frontal area per canopy volume and $h_{v}$ is the vegetation height. The frontal area of the vegetation for the unit area of the bed is $N_{v} \times h_{v} \times d_{v}$ and the canopy volume is $1 \times 1 \times h_{v}$, which is equal to the volume of the cuboid with the base of unit area and height of $h_{v}$. Then, the frontal area of vegetation per canopy volume, i.e., $a_{v}$ is equal to $a_{v}=\left(N_{v} \times h_{v} \times d_{v}\right) /\left(1 \times 1 \times h_{v}\right)=N_{v} d_{v}$, which has the unit of one over length (see Nepf 2012a). The dimensionless population density, $N_{v} \times d_{v}^{2}$, also can be written in terms of $a_{v}$ as $a_{v} d_{v}$. At the study site, on average, $a_{v}=2.281 / m$ and $a_{v} h_{v}=0.87$, which is considered as a dense canopy (Belcher et al. 2003).

\section{Data Analysis Method}

The zero-moment wave heights, $H_{m 0}$, at the offshore pressure sensor were calculated from the water surface elevation power spectral density, $S_{\eta \eta}$, as:

$H_{m 0}=4 \sqrt{\int S_{\eta \eta}(f) d f} \approx 4 \sqrt{\sum_{1}^{n} S_{\eta \eta, n} \Delta f_{n}}$
$S_{\eta \eta}(f)=\frac{1}{K_{p}^{2}(f)} \times \frac{S_{p p}(f)}{\rho^{2} g^{2}}$

$K_{p}(f)=\frac{\cosh \left(k d_{p}\right)}{\cosh \left(k h_{i}\right)}$

where $\rho$ is the water density, $g$ is the gravitational acceleration, $f$ is the frequency, $S_{p p}$ is the wave dynamic pressure spectrum, $k$ is the wave number, $h_{i}$ is the mean water depth in the bay at cross section $i, d_{p}$ is the distance of the pressure sampling point from the bed, and $K_{p}$ is the pressure response factor, or the pressure to surface elevation conversion factor.

The values of the wave energy in the marsh fringe, $E_{w}$, were calculated from the surface elevation power spectrum, using the wave orbital velocities as:

$E_{w}=\rho g \int S_{\eta \eta}(f) d f \approx \sum_{1}^{n} \frac{1}{8} \rho g\left(\frac{4}{\sqrt{2}} \sqrt{S_{\eta \eta, n} \Delta f_{n}}\right)^{2}$

Considering $u$ and $v$ as the horizontal components of the wave orbital velocities in $x$ and $y$ directions collected by an ADV, respectively, the $S_{\eta \eta}$ in Eq. (4), was calculated from the orbital velocities following the steps described by Wiberg and Sherwood (2008):

Table 1 Average properties of the vegetation at the study site

\begin{tabular}{lccc}
\hline Physical property & Unit & Mean & Standard deviation \\
\hline Stem population density, $N_{v}$ & Number of Stems $/ \mathrm{m}^{2}$ & 454 & 189 \\
Stem diameter, $d_{v}$ & $\mathrm{~mm}$ & 5.0 & 1.6 \\
Stem height up to bottom of first leaf & $\mathrm{cm}$ & 5.9 & 2.4 \\
Stem height, $h_{s}$ & $\mathrm{~cm}$ & 8.4 & 4.0 \\
Total height, $h_{v}$ & $\mathrm{~cm}$ & 38.3 & 10.3 \\
Leaves height & $\mathrm{cm}$ & 34.0 & 9.8 \\
Number of leaves & - & 5.0 & 1.6 \\
\hline
\end{tabular}




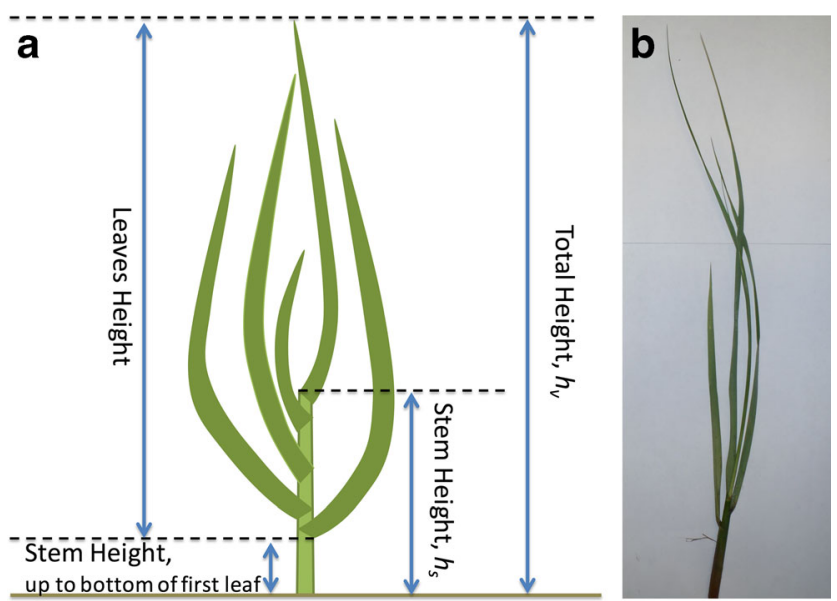

Fig. 4 a Schematic dimensions of Spartina alterniflora at deployment site (not scaled). b Plant sample

$S_{\eta \eta}(f)=\frac{S_{\tilde{u} \tilde{v}}(f)}{K_{\tilde{u} \tilde{v}}^{2}(f)}$

$S_{\tilde{u} \tilde{v}}(f)=S_{\tilde{u} \tilde{u}}(f)+S_{\tilde{v} \tilde{v}}(f)$

$K_{\tilde{u} \tilde{v}}(f)=\frac{2 \pi f \cosh \left(k d_{\tilde{v} \tilde{v}}\right)}{\sin h(k h)}$

where $S_{\tilde{u} \tilde{u}}$ and $S_{\tilde{v} \tilde{v}}$ are the power spectrum for the horizontal orbital velocity in $x$ and $y$ directions, respectively. $S_{\tilde{u} \tilde{v}}=S_{\tilde{u} \tilde{u}}$ $+S_{\tilde{v} \tilde{v}}$ is the power spectrum for the combined horizontal orbital velocities, $h$ is the mean water depth on the marsh, $d_{\tilde{u} \tilde{v}}$ is the distance of the velocity sampling point from the bed, and $K_{\tilde{u} \tilde{v}}$ is the surface elevation to the horizontal orbital velocity conversion factor.

Typically, the frequency range for applying the conversion factors, i.e., $K_{p}$ and $K_{\tilde{u} \tilde{v}}$, would be around $0.02 \leq \mathrm{f} \leq 0.2 \mathrm{~Hz}$ for the water depth of tens of meters, but this range should be extended to higher frequencies for the shallower water (Wiberg and Sherwood 2008). For the latter case, the higher frequency range for applying $K_{p}$ and $K_{\tilde{u} \tilde{v}}$ should be chosen cautiously. In fact, the inflation of the high frequency noise by $K_{p}$ and $K_{\tilde{u} \tilde{v}}$ can result in an overestimation of the wave energy and wave height. To prevent the high frequency energy from inflation, the conversion factors applied up to $f \leq 1 \mathrm{~Hz}$ in this study. Depending on the condition, it might be necessary to keep the conversion factor constant after a certain frequency limit in order to preserve the realistic spectral tail shape.

The mean current direction, $\bar{\theta}_{c}$, at each ADV location, was first calculated from the time-averaged horizontal velocities reported by each ADV in east, $\bar{u}_{E}$, and north, $\bar{u}_{N}$, directions, using $\bar{\theta}_{c}=a \tan \left(\bar{u}_{E} / \bar{u}_{N}\right)$, and then converted to the conventional meteorological direction. Note that all current velocities are averaged over a sampling burst of $1024 \mathrm{~s}$. The mean wave direction for an entire spectrum, $\bar{\theta}_{w}$, at each location was calculated as follows:

$\bar{\theta}_{w}=a \tan 2\left(\frac{\int \sin \theta_{1}(f) S_{\eta \eta}(f)}{\int \cos \theta_{1}(f) S_{\eta \eta}(f)}\right) \approx \operatorname{atan} 2\left(\frac{\sum_{1}^{n} \sin \theta_{1, n} S_{\eta \eta, n} \Delta f_{n}}{\sum_{1}^{n} \cos \theta_{1, n} S_{\eta \eta, n} \Delta f_{n}}\right)$

$\theta_{1}(f)=\operatorname{atan} 2\left(\frac{b_{1}(f)}{a_{1}(f)}\right)$

$a_{1}(f)=\frac{C_{\eta \tilde{u}}(f)}{\left(S_{\eta \eta}(f)\left(C_{\tilde{u} \tilde{u}}(f)+C_{\tilde{\mathcal{v}}}(f)\right)\right)^{0.5}}$

$b_{1}(f)=\frac{C_{\eta \tilde{v}}(f)}{\left(S_{\eta \eta}(f)\left(C_{\tilde{u} \tilde{u}}(f)+C_{\tilde{v} \tilde{v}}(f)\right)\right)^{0.5}}$

$C_{\tilde{u} \tilde{u}}(f)=\frac{S_{\tilde{u} \tilde{u}}(f)}{K_{\tilde{u} \tilde{v}}^{2}(f)}$

$C_{\tilde{v} \tilde{v}}(f)=\frac{S_{\tilde{v}}(f)}{K_{\tilde{v} \tilde{v}}^{2}(f)}$

$C_{\eta \tilde{u}}(f)=\frac{S_{\eta \tilde{u}}(f)}{K_{\tilde{u} \tilde{v}}(f) K_{p}(f)}$

$C_{\eta \tilde{v}}(f)=\frac{S_{\eta \tilde{v}}(f)}{K_{\tilde{u} \tilde{v}}(f) K_{p}(f)}$

where $\theta_{1}$ is the mean wave direction for each frequency, $S_{\eta \tilde{u}}$ and $S_{\eta \tilde{v}}$ are the water level and orbital velocity cross spectrum in $x$ and $y$ directions, respectively, and $a_{1}$ and $b_{1}$ are the normalized Fourier coefficients. Note that, except for Fig. 6, the direction in all figures and equations is presented with respect to the shoreline, as illustrated in Figs. 1 and 3. However, the direction in Fig. 6 follows the meteorological convention, measuring from the true north, increasing clockwise, i.e., $0^{\circ}$ from north, $90^{\circ}$ from east, $180^{\circ}$ from south, and $270^{\circ}$ from west.

The root mean square (RMS) value of the maximum orbital velocity was calculated from the power spectrum of the horizontal wave orbital velocities following Wiberg and Sherwood (2008):

$$
\begin{aligned}
\tilde{u}_{m-\mathrm{RMS}} & =\sqrt{2\left(\int S_{\tilde{u} \tilde{v}}(f) d f\right)} \\
& =\sqrt{2\left(\int S_{\tilde{u} \tilde{u}}(f) d f+\int S_{\tilde{v} \tilde{v}}(f) d f\right)}
\end{aligned}
$$


which was approximated for the discrete data series as:

$\tilde{u}_{m-\mathrm{RMS}} \approx \sqrt{2\left(\sum_{1}^{n} S_{\tilde{u} \tilde{v}, n} \Delta f_{n}\right)} \approx \sqrt{2\left(\sum_{1}^{n} S_{\tilde{u} \tilde{u}, n} \Delta f_{n}+\sum_{1}^{n} S_{\tilde{v} \tilde{v}, n} \Delta f_{n}\right)}$

As mentioned earlier, sampling points for both ADVs were located $0.14 \mathrm{~m}$ above the marsh platform. Therefore, only the data associated with the mean water depth at ADVs' locations larger than $h \geq 0.19 \mathrm{~m}$ were considered to allow at least a minimum of $5 \mathrm{~cm}$ of water on the top of the ADVs' sampling point. This margin was selected to ensure the submergence of the ADVs' sampling point during the passage of the wave trough. It is worth mentioning that under the storm conditions, the staff wave gauges may over-record the wave height, particularly when waves break at the marsh edge. This overestimation mainly occurred in the reading of the wave crest as a result of the wave run-up and water spray on the staff. Wave breaking close to the staff can intensify this effect. Because of that and for the quality assurance, no wave data from the staff wave gauges were used in this paper. A lesson learned is that staff wave gages should be deployed away from the marsh edge to avoid the impact of wave breaking.

\section{Results}

\section{Time Series of Water Level, Waves, and Currents}

Measurements of the water depths, wave properties, and current velocities on the marsh and in the bay were conducted from April 12 to 20, 2012. During this period, the marsh was inundated from April 13 to 17, 2012, except for a short period of time on April 14, 2012. To guarantee the submergence of the ADVs' sampling points, only the data from April 14 to 16, 2012 are analyzed and presented. Note that all the time in this paper is presented in Coordinated Universal Time, UTC.

The offshore water depth was approximately $1 \mathrm{~m}$, while the mean water depth landward of the marsh edge varied from 0.14 to $0.38 \mathrm{~m}$ with an average of $0.25 \mathrm{~m}$ (Fig. 5). The incident wave had a mean zero-moment wave height, $H_{m 0}$, of $0.35 \mathrm{~m}$ and peak wave period, $T_{p}$, of $2.9 \mathrm{~s}$. On average, the zeromoment wave heights decreased by $28 \%$ at cross section 2 and $52 \%$ at cross section 3 , compared to the incident waves.

The mean current velocity, $\tilde{u}$, is the temporal average of each sampling burst at $14 \mathrm{~cm}$ above the marsh ground, and should not be mistaken as the depth-averaged velocity. The direction of the current in the marsh fringe showed a variation from 124 to $214^{\circ}$, with the mean of $162^{\circ}$ (Fig. 6). Comparing Figs. 5 and 7 , the current direction variation is dependent on the water depth on the marsh. The current rotated toward the longshore direction as the water depth on the marsh surface increased (Figs. 5 and 7). The current direction remained nearly constant between cross sections 2 and 3. Unlike the current direction, the wave direction in the marsh fringe only varied within a limited range. With the mean changes from $-6.87^{\circ}$ at cross section 2 to $-11.07^{\circ}$ at cross section 3 , the wave direction rotated more toward north as it moved landward.

The time-averaged current velocity, $\tilde{u}$; the root mean square (RMS) of the maximum wave orbital velocity, $\tilde{u}_{m-R M S}$; the time-averaged cross-shore current velocity, $\tilde{u}_{C S}$; and the time-averaged longshore current velocity, $\tilde{u}_{L S}$, were all sampled $14 \mathrm{~cm}$ above the marsh platform surface in the wetland (Fig. 8). Since the marsh surface has a slight landward slope, the location of the velocity sampling point with respect to the water surface varies from cross sections 2 to 3 . It means that the measured velocity values at cross section 3 were at a slightly higher elevation in the water column compared to
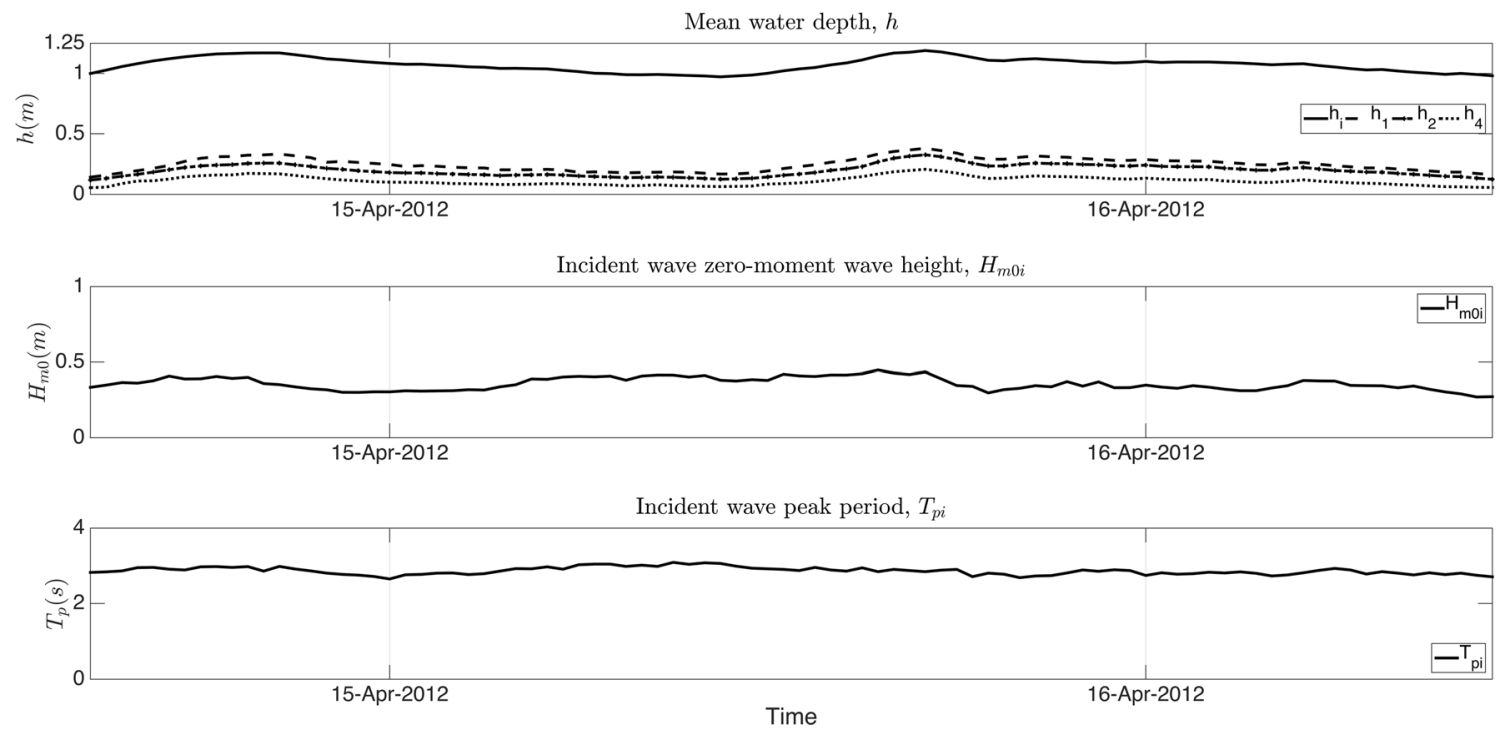

Fig. 5 Time series of water depth, wave height, and period 

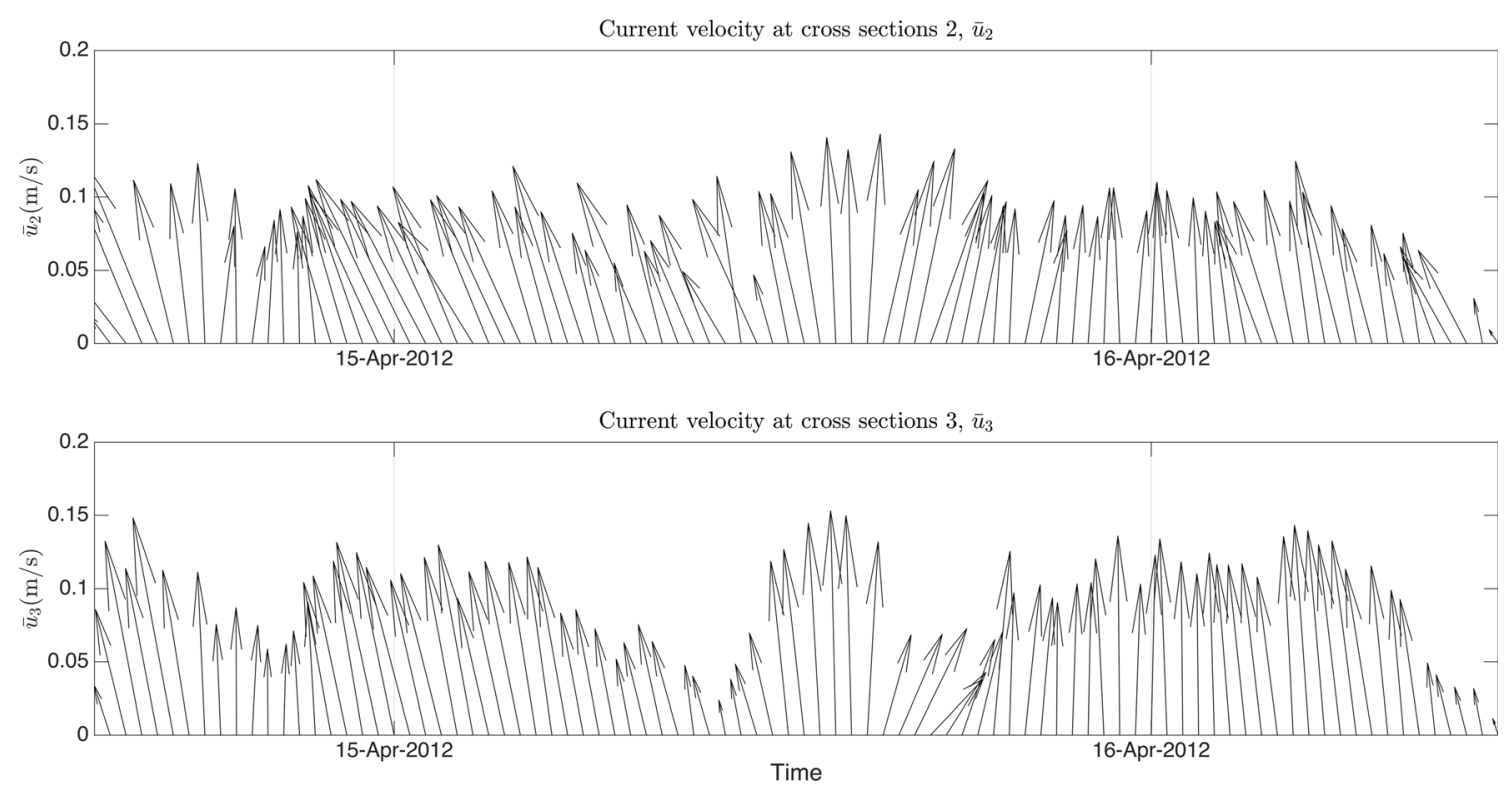

Fig. 6 Current velocity at cross sections 2 and 3

cross section 2 . The current velocity ranged from 0.01 to $0.15 \mathrm{~m} / \mathrm{s}$ with a mean of $0.1 \mathrm{~m} / \mathrm{s}$ at both cross sections 2 and 3. The RMS of the maximum wave orbital velocity ranged from 0.53 to $1.57 \mathrm{~m} / \mathrm{s}$ with a mean value of $0.73 \mathrm{~m} / \mathrm{s}$ at cross section 2 and ranged from 0.39 to $0.91 \mathrm{~m} / \mathrm{s}$ with a mean value of $0.67 \mathrm{~m} / \mathrm{s}$ at cross section 3 , which was much stronger than the mean current velocity. The cross-shore current velocity ranged from 0.01 to $0.15 \mathrm{~m} / \mathrm{s}$ with the absolute mean value of $0.08 \mathrm{~m} / \mathrm{s}$ at cross section 2 and ranged from -0.02 to $0.13 \mathrm{~m} / \mathrm{s}$ with the absolute mean value of $0.07 \mathrm{~m} / \mathrm{s}$ at cross section 3 . The longshore current velocity ranged from -0.13 to $0.1 \mathrm{~m} / \mathrm{s}$ with the absolute mean value of $0.05 \mathrm{~m} / \mathrm{s}$ at cross section 2 and ranged from -0.11 to $-0.004 \mathrm{~m} / \mathrm{s}$ with the absolute mean value of $0.06 \mathrm{~m} / \mathrm{s}$ at cross section 3 .

\section{Dependence of Current and Orbital Velocities in Saltmarsh Fringe on Incident Waves}

During the deployment, wave breaking on the marsh edge was observed. We hypothesized that wave breaking was the dominant contributor to the current measured in the marsh fringe. Such a hypothesis can be tested based on the correlation between the current velocities in the marsh fringe and the incident waves in the bay. Such a relationship can be established
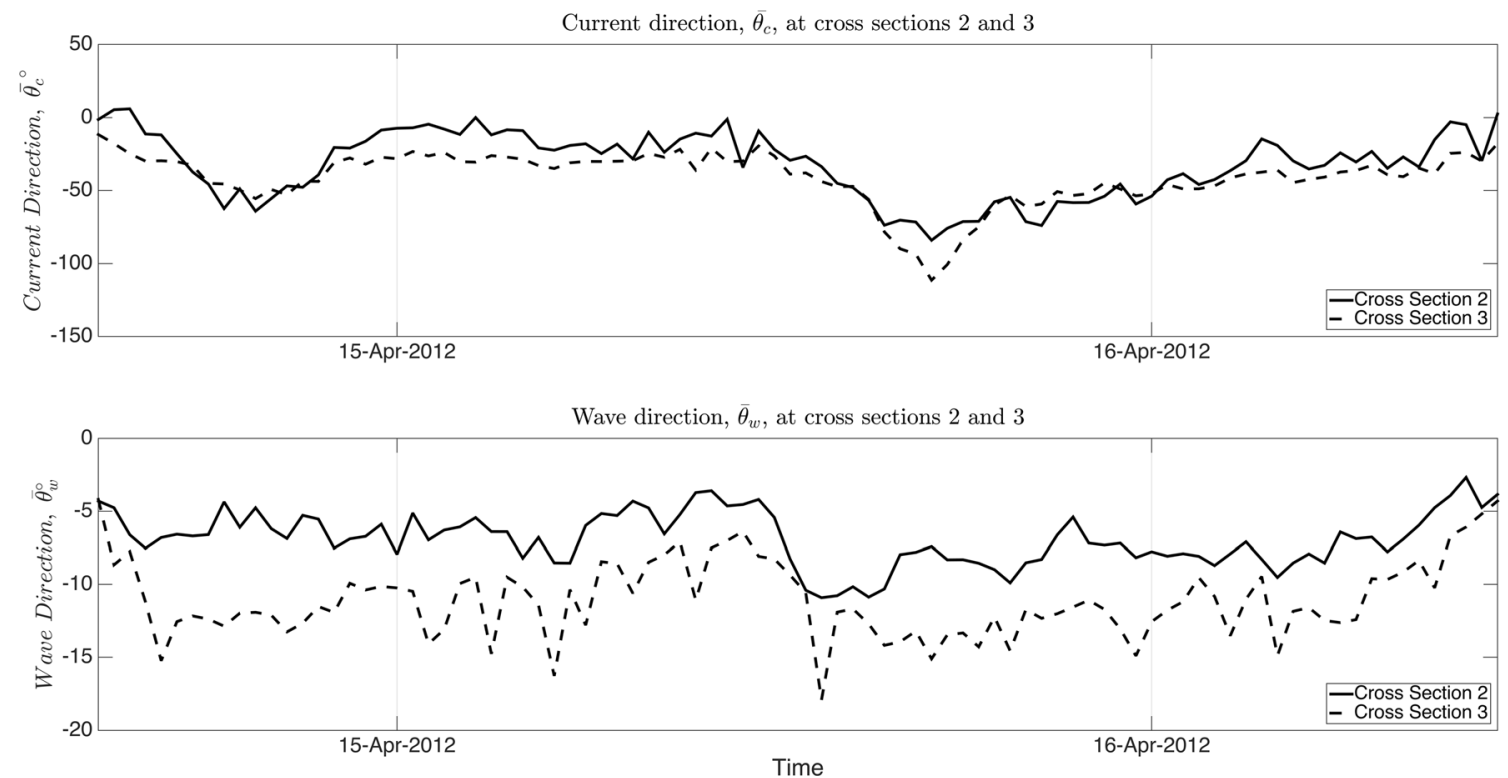

Fig. 7 Current direction (top), and wave direction (bottom) in the marsh fringe 
through the dimensional analysis according to the basic fluid mechanics. The mean current velocity is considered to be a function of the incident wave properties, i.e., the zero-moment wave height, $H_{m 0 i}$; mean wave period, $T_{i}$; and wavelength, $L_{i}$; water depth inside the bay, $h_{i}$; and water depth on the marsh, $h$; as well as the vegetation properties, i.e., the stem density, $N_{v}$; stem height, $h_{S}$; and stem diameter, $d_{v}$. The wavelength of the incident waves has the characteristics of both water depth in the bay and the incident wave period, which was almost constant throughout the measurement. Therefore, the current velocity averaged over each sampling burst, $\bar{u}$, may be expressed as a function of $H_{m 0 i}, L_{i}, h, N_{v}, h_{s}, d_{v}$ and $\nu$ :

$f_{1}\left(\bar{u}, H_{m 0 i}, L_{i}, h, N_{v}, h_{s}, d_{v}, \nu\right)$

Using the Buckingham $\pi$ theorem for dimensional analysis, $f_{1}$ can be written in terms of the dimensionless groups as $f_{1}\left(\frac{\bar{u} h}{\nu}, \frac{H_{m 0 i}}{h}, \frac{h}{L_{i}}, \frac{h}{h_{s}}, \frac{h}{d_{v}}, \frac{1}{h^{2} N_{v}}\right)=0$. These dimensionless groups are re-arranged and combined to represent the effect of a depth-limited wave breaking on the marsh edge by using a ratio similar to the breaker index, $H_{m 0 i} / h$, the effect of the incident waves by using the incident wave steepness, i.e., $H_{m 0 i} / L_{i}$, the effect of inundation depth and stem height by using the vegetation submergence ratio, i.e., $h / h_{s}$, the effect of stem diameter by using $h / d_{v}$, and the effect of stem density by using $1 / N_{v} d_{v}^{2}$. Then, Eq. (18) can be written as:

$\frac{\bar{u} h}{\nu}=F_{1}\left(\frac{H_{m 0 i}}{h}, \frac{H_{m 0 i}}{L_{i}}, \frac{h}{h_{s}}, \frac{h}{d_{v}}, \frac{1}{N_{v} d_{v}^{2}}\right)$

The term on the left-hand side of Eq. (19), i.e., $\bar{u} h / \nu$, represents the Reynolds-type number calculated from the time- averaged current velocity in the marsh fringe, $\bar{u}$; the mean water depth on the marsh, $h$; and the kinematic viscosity of the water, $\nu$. The first term on the right-hand side of Eq. (19), $H_{m 0 i} / h$, represents the depth-limited wave breaking, as we hypothesized wave breaking was the major driving force for the measured current in the marsh fringe. Note that although $H_{m 0 i} / h$ is similar to the wave breaker index, unlike the breaker index that is the ratio of the local wave height to the local water depth, the $H_{m 0 i} / h$ is the ratio of incident wave height over local water depth. The wave steepness, $H_{m 0 i} / L_{i}$, represents the incident wave steepness. The submergence ratio, $h /$ $h_{s}$, has a direct impact on the current velocity in the marsh fringe, as its value plays an important role in the depth-limited wave breaking and the velocity profile of the landward and undertow flows on the marsh. The ratio of $h / d_{v}$ has a similar but less important role as the submergence ratio, since its effect can be represented by $h / h_{s}$ and $1 /\left(N_{v} \times d_{v}^{2}\right)$. The dimensionless stem density of vegetation, $N_{v} \times d_{v}^{2}$, has an inverse relationship with the flow in the marsh fringe. The larger value of $N_{v} \times d_{v}^{2}$ represents the denser vegetation coverage, which results in a higher resistance to the flow and thus weaker velocity. Resistant role of the vegetation has been investigated in the literature through solving the Navier-Stokes equations with vegetation (e.g., Marsooli and Wu 2014). The Navier-Stokes momentum equation governing the flow over vegetation can be written as $\frac{\partial u}{\partial t}+(\nabla . u) u=-\frac{1}{\rho} F_{b}-\frac{1}{\rho} \nabla p$ $+\nabla$. $(\nu \nabla u)$, where $u$ is the velocity vector, $t$ is the time, $p$ is the pressure, $\nu$ is the molecular and turbulent kinematic viscosity of water, $F_{b}=\rho \mathrm{g}+F_{v}$ is the external body force, and $F_{v}$ is the vegetation force. The $F_{v}$ represents the flow-induced drag force, i.e., $0.5 \rho C_{D} N_{v} d_{v} u|u|$, plus the inertia force, i.e., $0.5 \rho C_{M} N_{v} d_{v}^{2} \frac{\partial u}{\partial t}$, where $C_{D}$ is drag coefficient and $C_{M}$ is inertia
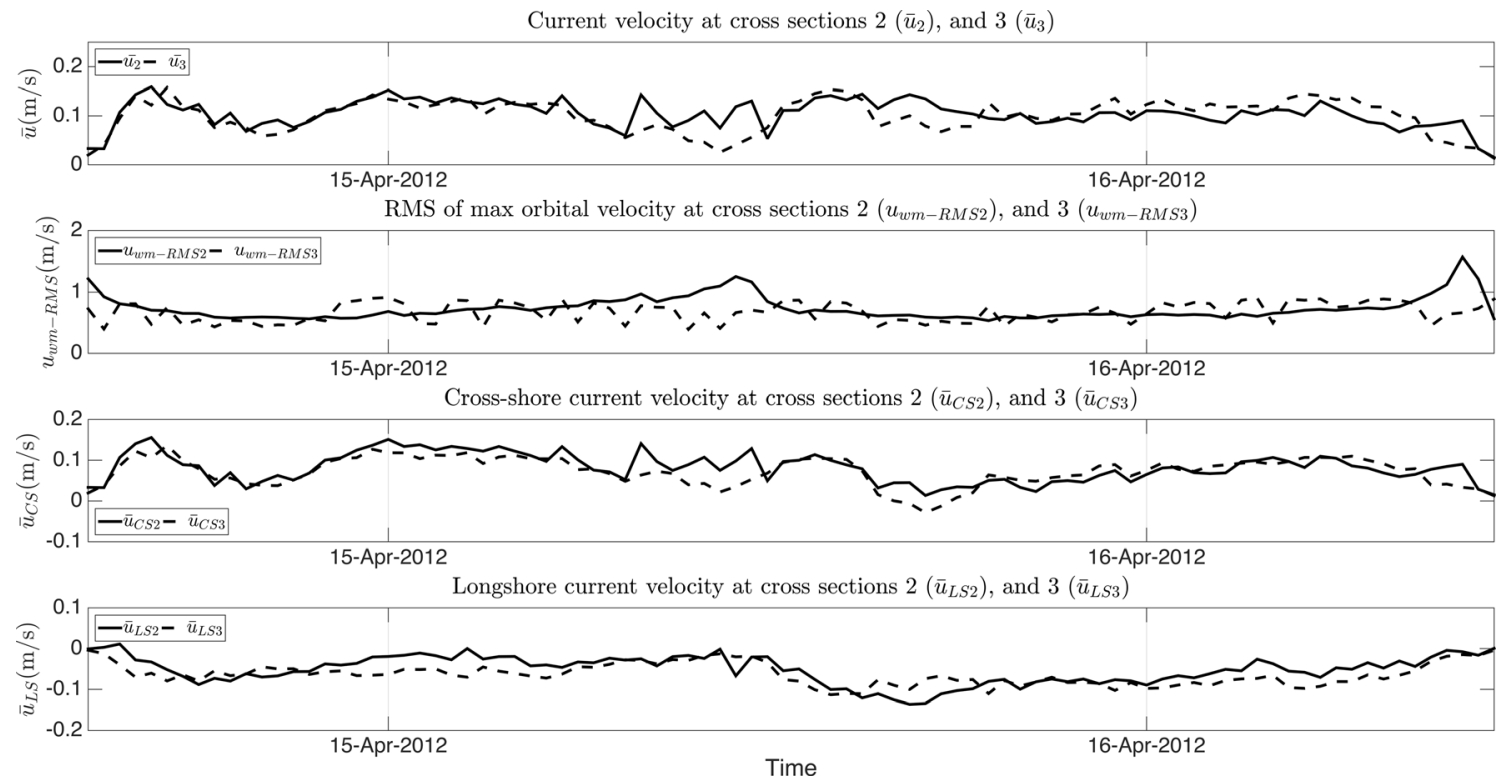

Fig. 8 Current and orbital velocities in the marsh fringe 
coefficient (Marsooli and $\mathrm{Wu}$ 2014). The external body force term in the Navier-Stokes equation for vegetated flows, i.e., $F_{b}$, is a function of the vegetation population density and stem height, indicating the role of vegetation in the momentum balance of the flow through wetland vegetation.

Plotting the measured data following the relationship of Eq. (19) shows that the mean current velocities on the marsh surface were primarily controlled by the incident waves in the bay as well as by the inundation depth, submergence ratio and vegetation density in the marsh fringe. This relationship, as illustrated in Fig. 9, can be expressed as:

$$
\frac{\bar{u} h}{\nu}=A_{I}\left(\frac{H_{m 0 i}}{h}\right)^{B_{I 1}}\left(\frac{H_{m 0 i}}{L_{i}}\right)^{B_{I 2}}\left(\frac{h}{h_{s}}\right)^{B_{I 3}}\left(\frac{h}{d_{v}}\right)^{B_{I 4}}\left(\frac{1}{N_{v} d_{v}^{2}}\right)^{B_{I 5}}
$$

As this study was carried out for a single type of vegetation, all the vegetation properties, i.e., the $h_{s}, d_{v}$ and $N_{v}$ remained constant during the study. Therefore, the values of $A_{I}$ and $B_{I 1}$ to $B_{I 5}$ are specific for this type of vegetation, and likely to be different at a different site with different vegetation properties. Additionally, due to the fact that the last term on the right-hand side of Eq. (20), i.e., $1 / N_{v} d_{v}^{2}$, is constant in this study, the value of $\mathrm{B}_{\mathrm{I} 5}$ is assumed to be 1 . This assumption remains to be evaluated for different types of vegetation in future studies. To define universal values for the coefficients in Eq. (20), additional studies with different types of vegetation are required. Using the best-fitted line to the data, for specific vegetation at this study site, coefficients $A_{I}$ and $B_{I}$ were obtained as $A_{I}=2.081 \times 10^{5}, B_{I 1}=-1, B_{I 2}=2, B_{I 3}=$ $0.0333, B_{I 4}=0.0333, B_{I 5}=1$, with the coefficient of determination, $R^{2}=0.61$, for cross section 2 . This confirms that waves were the dominant driver of the measured

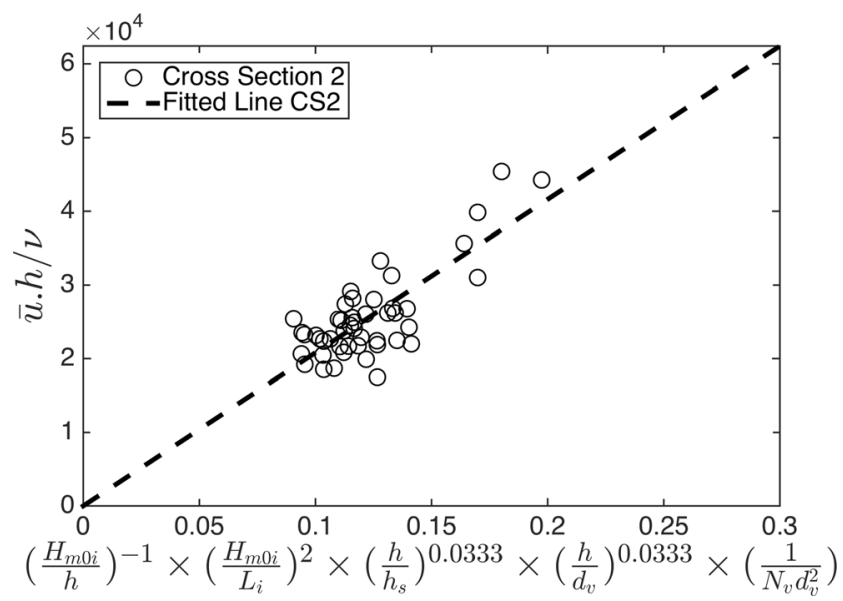

Fig. 9 Relationship between the mean current velocity in the marsh fringe and the combined effects of the incident waves in the bay, inundation depth, submergence ratio and vegetation density in the marsh fringe for $d_{v}=0.005 \mathrm{~m}, h_{s}=0.084 \mathrm{~m}$, and $N_{v}=454 \mathrm{stems} / \mathrm{m}^{2}$. The fitted line represents Eq. (20) currents in the marsh fringe, especially near the marsh edge (Fig. 9). It can be expected that as incident waves propagate landward and wave energy is dissipated by vegetation, the correlation between the current and offshore waves became weaker because wave effects decreased in comparison with other forcing agents.

Furthermore, we analyzed the relationship between the root mean square (RMS) values of the maximum orbital velocity of transmitted waves into the marsh fringe with the incident waves in the bay. Following the argument for Eqs. (18) and (19), the RMS value of the maximum orbital velocity in the marsh fringe, $\tilde{u}_{m-\mathrm{RMS}}$, may be expressed as a function of $H_{m 0 i}, L_{i}, h, N_{v}, h_{s}, d_{v}$ and $g$, or $f_{2}\left(\tilde{u}_{m-\mathrm{RMS}}, H_{m 0 i}, L_{i}, h, N_{v}, h_{s}, d_{v}, g\right)=0$. Using the Buckingham $\pi$ theorem, $f_{2}$ can be written in terms of the dimensionless groups as $f_{2}\left(\frac{\widetilde{u}_{m-\mathrm{RMS}}}{\sqrt{g h}}, \frac{H_{m 00}}{h}, \frac{h}{L_{i}}, \frac{h}{h_{s}}, \frac{h}{d_{v}}, \frac{1}{h^{2} N_{v}}\right)=0$. By re-arranging and combining the dimensionless groups to incorporate the effects of the depth-limited wave breaking, $H_{m 0 i} / h$; incident waves, $H_{m 0 i} / L_{i}$; water depth on the marsh, $h / h_{s}$; vegetation diameter, $h / d_{v}$; and the vegetation density, $1 / N_{v} d_{v}^{2}$, the relationship can be obtained as:

$\frac{\tilde{u}_{m-\mathrm{RMS}}}{\sqrt{g h}}=F_{2}\left(\frac{H_{m 0 i}}{h}, \frac{H_{m 0 i}}{L_{i}}, \frac{h}{h_{s}}, \frac{h}{d_{v}}, \frac{1}{N_{v} d_{v}^{2}}\right)$

The term on the left-hand side of Eq. (21) represents the Froude-type number based on the RMS value of the maximum wave orbital velocity, $\tilde{u}_{m-\mathrm{RMS}}$, and the water depth in the marsh fringe, $h$. The RMS value of the maximum orbital velocity in the marsh fringe, $\tilde{u}_{m-\mathrm{RMS}}$, is calculated using Eqs. (16) and (17). As shown in Fig. 10, the RMS value of the maximum orbital velocity in the marsh fringe has a close relationship with the incident waves in the bay, submergence ratio and vegetation density as:

$\frac{\tilde{u}_{m-\mathrm{RMS}}}{\sqrt{g h}}=A_{I I}\left(\frac{H_{m 0 i}}{h}\right)^{B_{I I 1}}\left(\frac{H_{m 0 i}}{L_{i}}\right)^{B_{I I 2}}\left(\frac{h}{h_{s}}\right)^{B_{I 3}}\left(\frac{h}{d_{v}}\right)^{B_{I I 4}}\left(\frac{1}{N_{v} d_{v}^{2}}\right)^{B_{I I 5}}$

Following the same argument for Eq. (20), the values of $A_{I I}$ and $B_{I I 1}$ to $B_{I I 5}$ are specific for this type of vegetation with the assumption of $B_{I I 5}=1$, and they are likely to be different at a different site with different vegetation properties. To define universal values for the coefficients in Eq. (22), additional studies with different types of vegetation are required. Applying the best-fitted line to the data, coefficients $A_{I I}$ and $B_{I I}$ in Eq. (22) for the specific vegetation at this study site were determined as $A_{I I}=3.137 \times 10^{-4}, B_{I I 1}=1, B_{I I 2}=-2 / 3, B_{I I 3}=$ $0.0333, B_{I I 4}=0.0333, B_{I I 5}=1$, with $R^{2}=0.75$ for cross section 2 .

Note that Eqs. (20) and (22) are introduced to characterize the physics of wave-generated currents in the marsh fringe 


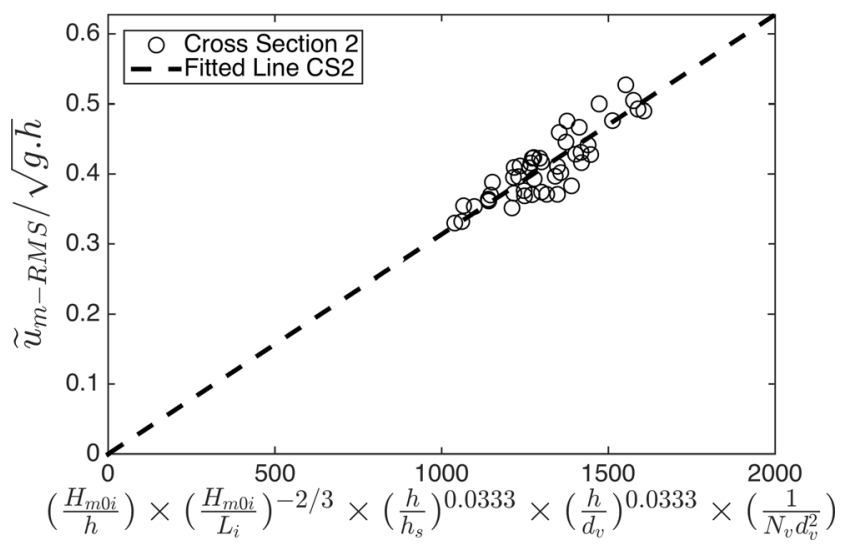

Fig. 10 Relationship between the RMS values of the maximum orbital velocity of waves in the marsh fringe and the combined effects of the incident waves in the bay, inundation depth, submergence ratio and vegetation density in the marsh fringe for $d_{v}=0.005 \mathrm{~m}, h_{s}=0.084 \mathrm{~m}$, and $N_{v}=454 \mathrm{stems} / \mathrm{m}^{2}$. The fitted line represents Eq. (22)

zone, and to test the hypothesis that incident waves and wave breaking are the major driving force for the measured current in the marsh fringe. Although the general forms of Eqs. (20) and (22) may remain unchanged for other sites with different vegetation properties, the coefficients $A_{I}, B_{I}, A_{I I}$, and $B_{I I}$ need to be re-calibrated. The values of coefficients $A_{I}, B_{I}, A_{I I}$, and $B_{I I}$ presented here are only valid for $d_{v}=0.005 \mathrm{~m}, h_{s}=0.084 \mathrm{~m}$, $N_{v}=454 \mathrm{stems} / \mathrm{m}^{2}, a_{v}=2.281 / \mathrm{m}$, and $N_{v} \times d_{v}^{2}=0.0114$. The universal values of the coefficients could be defined by repeating this study for different vegetation. Ultimately, the singlepoint time-averaged velocity in this study could be replaced by a depth-averaged velocity if the velocity profile is known.

\section{Dependence of Current Velocity in Saltmarsh Fringe on Local Wave Energy}

To understand the measured currents near the edge in the saltmarsh fringe zone, the relationships between the waves in the marsh fringe with the longshore and cross-shore components of the current velocity in the marsh fringe are analyzed. The principle of the wave radiation stresses has been successfully used to predict the longshore current on a beach (Longuet-Higgins 1970a, b; Komar 1979; Chen et al. 2003). Komar and Inman (1970) proposed an equation to estimate the mean longshore current at the mid-surf zone, $\bar{V}_{l}$, as a function of the breaking wave height, $H_{b}$, and breaking wave angle, $\alpha_{b}$, as follows:

$\bar{V}_{l}=1.17\left(g H_{b}\right)^{0.5} \sin \alpha_{b} \cos \alpha_{b}$

Following the same principle and replacing the wave parameters at the breaking point with the ones inside the fringe zone of the marsh where a majority of waves were broken, i.e., $\left(g H_{b}\right)^{0.5}$ with $\left(8 g E_{w} / \rho\right)^{0.25}$ and $\alpha_{b}$ with $\bar{\theta}_{w}$, similar relationships can be developed for the current velocities in the saltmarsh fringe. Incorporating the effect of the submergence ratio of the vegetation in the fringe zone, $h / h_{s}$, and the vegetation population density, $1 /\left(N_{v} d_{v}^{2}\right)$, the relationships as depicted in Figs. 11 and 12, can be obtained for the longshore component, $\bar{u}_{\mathrm{LS}}$, and the cross-shore component, $\bar{u}_{\mathrm{CS}}$, of the current velocity respectively as:

$\left|\bar{u}_{L S}\right|_{n}=A_{I I I}\left(\frac{h_{n}}{h_{S}}\right)\left(\frac{1}{N_{v} d_{v}^{2}}\right)\left(\frac{g}{\rho} E_{w 2}\right)^{0.25} \sin \left|\bar{\theta}_{w 2}\right| \cos \left|\bar{\theta}_{w 2}\right|$

$\bar{u}_{C S n}=f_{3}\left(\frac{h_{n}}{h_{s}}, \frac{1}{N_{v} d_{v}^{2}},\left(\frac{8 g}{\rho} E_{w 2}\right)^{0.25} \cos \left|\bar{\theta}_{w 2}\right|\right)$

where subscript 2 is referring to cross section 2 , and subscript $n$ is referring to the cross section $n$ with $n$ equal to 2 and 3 . Subscript $n$ indicates that for the submergence ratio, the local values at each location, i.e., cross sections 2 and 3, were used in the equations. Unlike the submergence ratio, for the wave energy, only the values close to the edge, i.e., cross section 2 , where most of the waves broke, were used in the equations. Following the same argument for Eq. (20), it is assumed that $1 / N_{v} d_{v}^{2}$ has a power of one, i.e., $\left(1 / N_{v} d_{v}^{2}\right)^{1}$, in Eqs. (24) and (25). This assumption is yet to be tested with different types of vegetation in future studies. Applying the best-fitted line to the longshore data yields the coefficient $A_{I I I}=0.0029$ with $R^{2}=$ 0.64 for cross section 2. Following the same argument for Eqs. (20) and (22), the value of $A_{I I I}$ is specific for this type of vegetation, and likely to be different at a different site with different vegetation properties. The correlation of the longshore current velocity and local waves in the marsh fringe is similar to the correlation of the current velocity in the marsh fringe and offshore waves, which provides strong evidence in support of our hypotheses that the observed currents in the

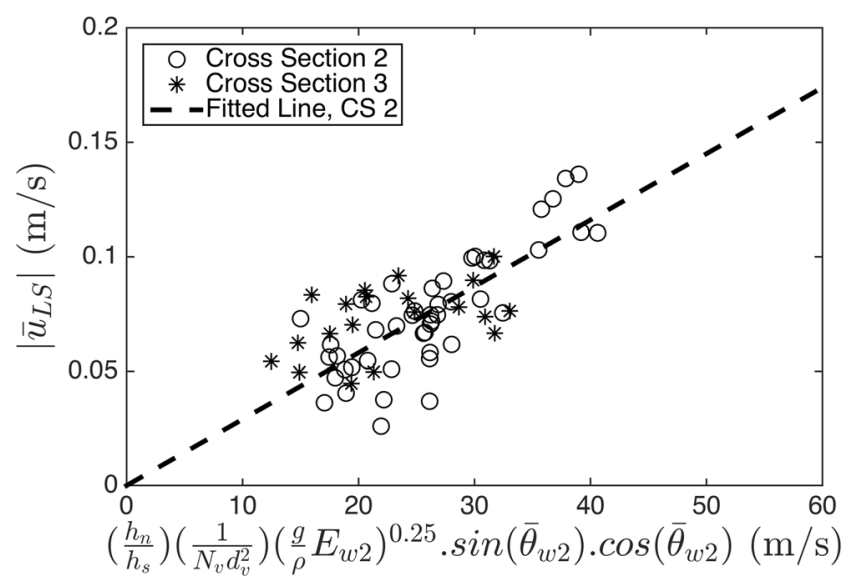

Fig. 11 Relationship between the longshore current velocity in the marsh fringe with the combined effects of the wave energy, submergence ratio and vegetation density in the marsh fringe for $d_{v}=0.005 \mathrm{~m}, h_{s}=0.084 \mathrm{~m}$, and $N_{v}=454 \mathrm{stems} / \mathrm{m}^{2}$. The fitted line represents Eq. (24) 


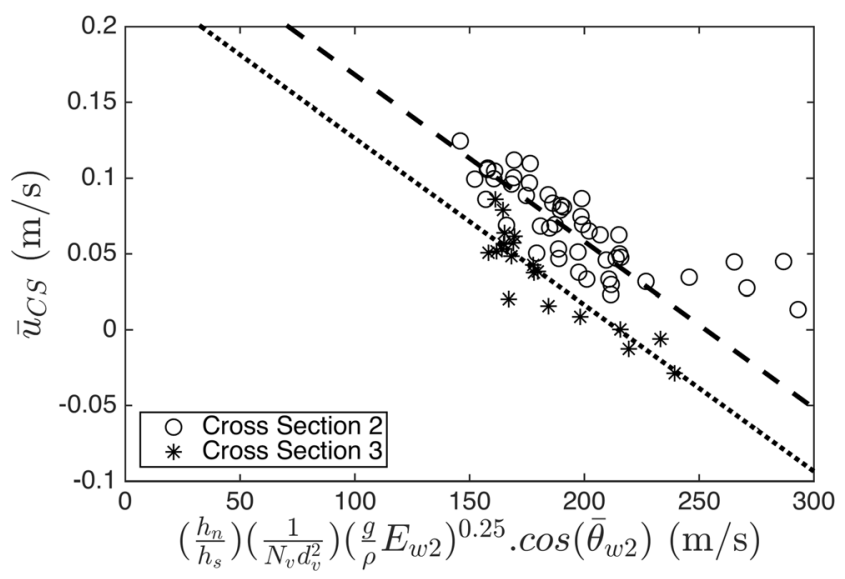

Fig. 12 Relationship between the cross-shore current velocity in the marsh fringe with the combined effects of the wave energy, submergence ratio, and vegetation density in the marsh fringe for $d_{v}=$ $0.005 \mathrm{~m}, h_{s}=0.084 \mathrm{~m}$, and $N_{v}=454 \mathrm{stems} / \mathrm{m}^{2}$

marsh fringe were wave driven.

A comparison of Figs. 11 and 12 shows that, unlike the longshore current velocity which increased with the wave energy in the marsh fringe, the cross-shore current velocity decreased as the wave energy increased. This descending trend resulted in negative velocities for the large wave energy in the fringe zone. This suggests that the cross-shore current $14 \mathrm{~cm}$ above the bed was pointing seaward in the case of large local wave energy or greater inundation depth. These negative readings of the ADVs were associated with the greater water depth in the fringe zone (Fig. 13). It means that as the water depth increased on the marsh surface, the cross-shore current velocity at the ADVs' sampling elevation decreased. Negative values were recorded during the greater water depths at cross section 3. Although, no negative values were recorded at cross section 2 , it would occur if the water depth increased further.

This cross-shore velocity trend indicates the presence of an undertow in the fringe zone of the inundated saltmarsh during the study period (Fig. 14). The undertow is an offshoredirected flow near the bed, which is generated in the surf zone

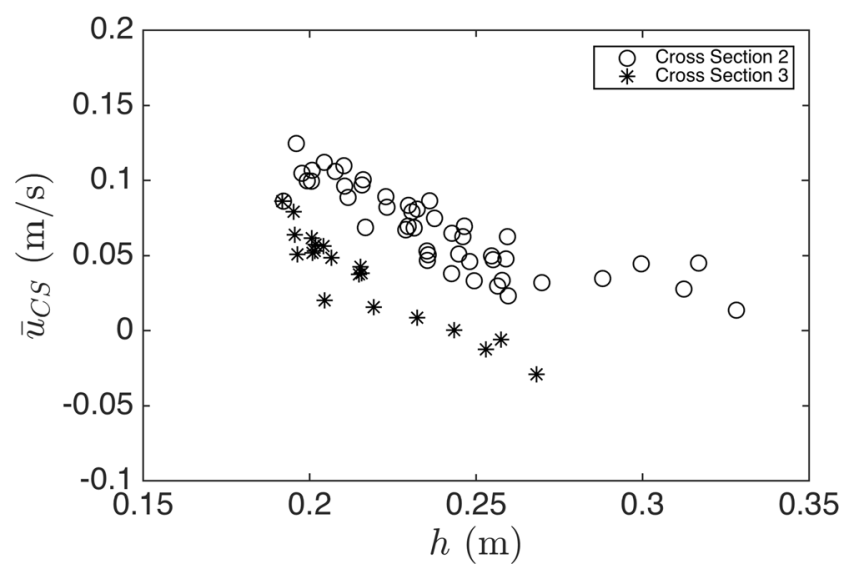

Fig. 13 Relationship between the cross-shore current velocity and the water depth in the marsh fringe landward of the breaking point on a beach. As the waves break, the wave momentum flux transports water mass in the breaking area (or roller) toward the shoreline and elevates the mean water level (or wave setup) by pushing the water against the shore. This near-surface onshore-directed mass transport will be balanced by a near-bed offshore undertow, which is generated by the pressure gradient resulting from the wave setup and the vertical variation of the excess momentum flux due to the wave motion (or radiation stress). The ADVs' sampling points had a constant distance from the ground equal to $14 \mathrm{~cm}$ throughout the study period. For most of the time, the ADVs recorded velocities toward the saltmarsh. As the water depth increased, the undertow region developed upward in the water column, and thus the smaller velocities were measured at the fixed sampling elevation. Eventually, when the water depth increased considerably on the marsh fringe surface, the undertow region reached the ADVs' sampling location. At that point, the ADVs recorded the reverse flow toward the sea and did not measure the flow toward the saltmarsh. This explains the decreasing trend of the cross-shore current velocity as the local wave energy or the water depth in the marsh fringe increased.

\section{Dependence of Current Direction in Saltmarsh Fringe on Local Wave Energy}

Similar to the current velocity in the marsh fringe, the current direction in the marsh fringe can be estimated by the wave energy, vegetation submergence and vegetation density in the marsh fringe. To do so, the current direction is considered to be a function of the local wave energy at the marsh edge, $E_{w 2}$; current energy at the marsh edge; vegetation submergence ratio; and vegetation density. The local wave energy in the marsh fringe that contributed to the longshore and crossshore currents are $E_{w 2} \cdot \sin \left|\bar{\theta}_{w 2}\right| \cdot \cos \left|\bar{\theta}_{w 2}\right|$ and $E_{w 2} \cdot \cos \left|\bar{\theta}_{w 2}\right|$, respectively. The longshore and cross-shore components of the current energy in the fringe zone are $0.5 \rho h_{2}\left|\bar{u}_{L S}\right|^{2}$ and $0.5 \rho h_{2} \bar{u}_{C S}^{2}$, respectively. Then, the dimensionless energy in the marsh fringe can be written for the longshore direction as:

$\widehat{E}_{L S_{2}}=\frac{0.5 p h\left|\bar{u}_{L S}\right|_{2}^{2}}{E_{w 2} \cdot \operatorname{Sin}\left|\bar{\theta}_{w 2}\right| \cdot \cos \left|\bar{\theta}_{w 2}\right|}$

Using the dimensionless flow energy in the marsh fringe along with the vegetation submergence ratio, $h_{2} / h_{s}$, and the vegetation population density in the marsh fringe, $N_{v} d_{v}^{2}$, the current direction at the fixed elevation in the fringe zone can be expressed as:

$$
\left|\bar{\theta}_{c}\right|_{2}=A_{\mathrm{IV}}\left(\frac{360}{2 \pi}\right) a \tan \left(B_{I V} \times \frac{h_{2}}{h_{s}} \times \frac{1}{N_{v} d_{v}^{2}} \times \widehat{E}_{L S_{2}}\right)
$$


Fig. 14 Schematic relationship between the water depth and the cross-shore current velocity profile at cross section 3 for three different water depth (not scaled)

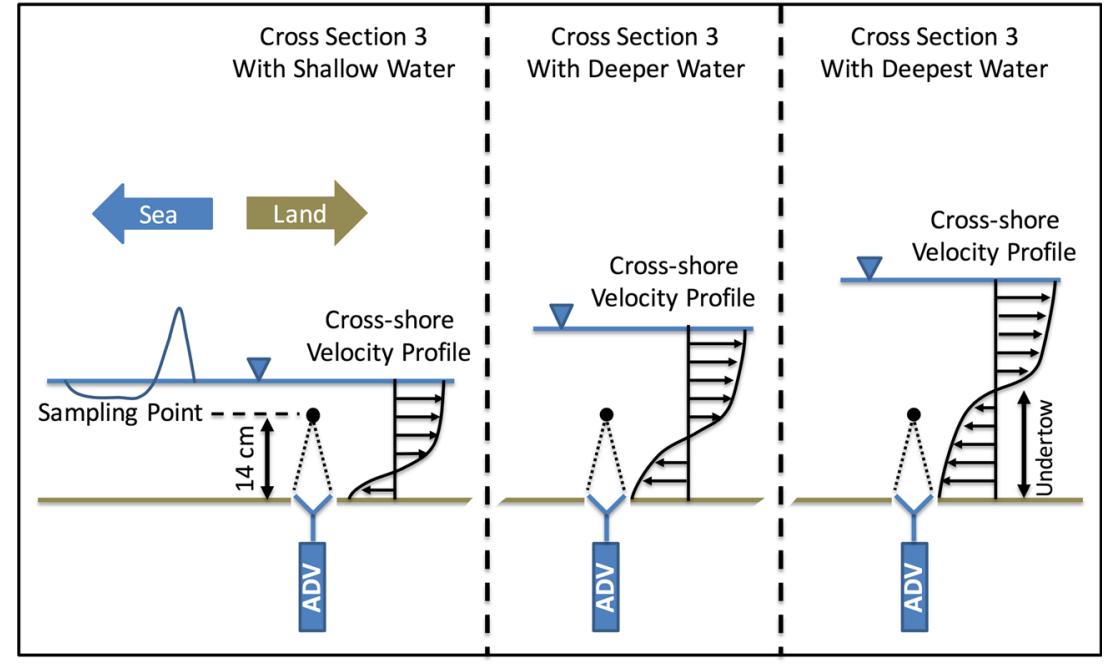

Similar to Eq. (20), it is assumed that $1 / N_{v} d_{v}^{2}$ has a power of 1, i.e., $\left(1 / N_{v} d_{v}^{2}\right)^{1}$, in Eq. (27). This assumption remains to be tested with different types of vegetation. Substituting Eq. (24) into Eq. (26) and re-writing
Eq. (27), the current direction within the marsh fringe can be expressed as a function of the waves, inundation depth, submergence ratio, and vegetation density in the fringe zone as:

$\left|\bar{\theta}_{c}\right|_{2}=A_{V}\left(\frac{360}{2 \pi}\right) \operatorname{atan}\left(B_{V}\left(\frac{h_{2}}{h_{s}} \times \frac{1}{N_{v} d_{v}^{2}}\right)^{3}\left(0.5 h_{2}\right)\left(\frac{\rho \mathrm{g}}{E_{w 2}}\right)^{0.5} \sin \left|\bar{\theta}_{w 2}\right| \cos \left|\bar{\theta}_{w 2}\right|\right)$

where $(360 / 2 \pi)$ converts the radian to degrees and $\left(0.5 h_{2}\right) \times(\rho g /$ $\left.E_{w 2}\right)^{0.5} \approx 2\left(h_{2} / H_{m 0-2}\right)$, and $H_{m 0-2}$ is a zero-moment wave height at cross section 2. Applying the best-fitted line to the longshore data yields the coefficients $A_{I V}=1$ and $B_{I V}=0.035$ with $R^{2}=0.86$ and $A_{V}=1.18$ and $B_{V}=2.38 \times 10^{-7}$ with $R^{2}=0.73$, for cross section 2 , indicating a very strong correlation between the current direction, local wave energy, submergence ratio, and vegetation density which supports our hypothesis of wave dominance in the marsh fringe flow. Following the same argument for Eqs. (20), the values of $A_{I V}, B_{I V}, A_{V}$, and $B_{V}$ are specific for this type of vegetation, and likely to be different at a different site with different vegetation properties. Figure 15 and Eq. (27) show that, for a small value of $\widehat{E}_{\mathrm{LS}} \times\left(h / h_{s}\right) \times\left(N_{v} d_{v}^{2}\right)^{-1}$, the current at the sampling elevation flowed toward the marsh, perpendicular to the shoreline. As the value of $\widehat{E}_{\mathrm{LS}} \times\left(h / h_{s}\right) \times\left(N_{v} d_{v}^{2}\right)^{-1}$ became larger, the current in the fringe zone became more parallel to the shoreline. Similar trend is shown in Fig. 16 as the current direction is presented as a function of the waves, inundation depth, submergence ratio, and vegetation density in the fringe zone. The variability of the current direction at a fixed elevation above the marsh fringe indicates a complex threedimensional (3D) structure of the wave-driven currents in the margin of flooded saltmarshes. Complex 3D flow patterns of wave-induced currents on an idealized wetland were observed in recent numerical simulations (Ma et al. 2013).

\section{Discussion}

The physics that generate currents within fringe zone of inundated saltmarsh can be explained using similar wave-driven processes on a coral reef. The near-edge wave-induced currents over the reef are generated mainly by the wave breaking

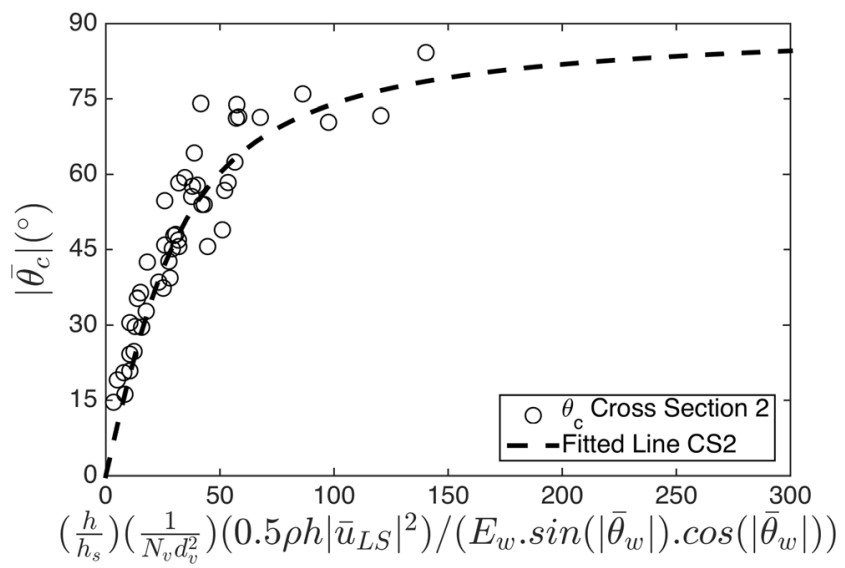

Fig. 15 Relationship between the current direction in the marsh fringe with the combined effects of the dimensionless longshore flow energy, submergence ratio and vegetation density in the marsh fringe for $d_{v}=$ $0.005 \mathrm{~m}, h_{s}=0.084 \mathrm{~m}$, and $N_{v}=454 \mathrm{stems} / \mathrm{m}^{2}$. The fitted line represents Eq. (27) 


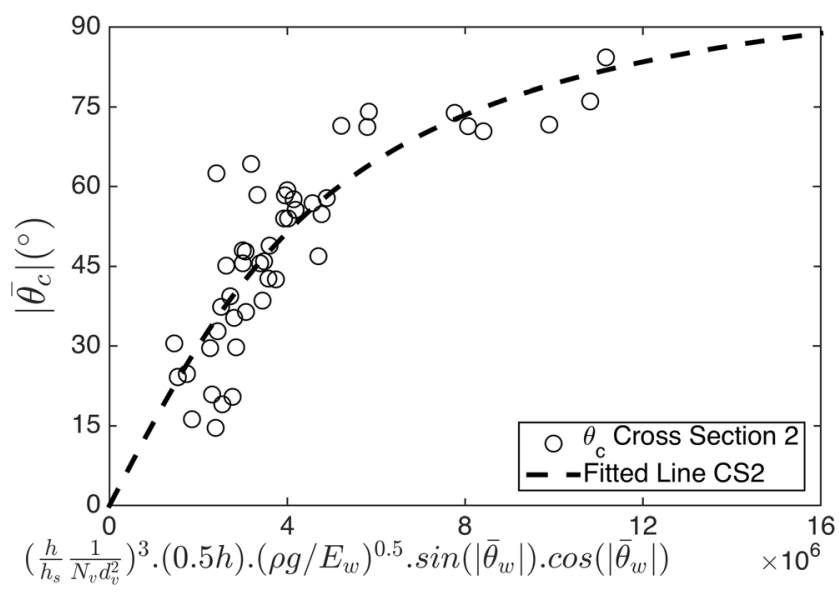

Fig. 16 Relationship between the current direction in the marsh fringe with the combined effects of the local wave energy, inundation depth, submergence ratio, and vegetation density in the marsh fringe for $d_{v}=$ $0.005 \mathrm{~m}, h_{s}=0.084 \mathrm{~m}$, and $N_{v}=454 \mathrm{stems} / \mathrm{m}^{2}$. The fitted line represents Eq. (28)

on the reef offshore face and the reef top (e.g., Monismith 2007). Using this concept, wave radiation stress gradients can be connected with the forces acting on the current to calculate the wave-driven current over the reef (e.g., Symonds et al. 1995; Gourlay 1996; Hearn 1999; Tartinville and Rancher 2000; Symonds and Black 2001; Gourlay and Colleter 2005; Monismith 2007). Similar to coral reefs, typical coastal wetlands have steep scarps of various heights, and wave breaking and current generation inland of a marsh edge have been reported in the literature (e.g., Tonelli et al. 2010; Truong et al. 2014). Considering the geometric and physical similarities, the same concept can be applied to the margin of inundated saltmarshes where wave radiation stress gradients drive the current in the marsh fringe under storm conditions. However, the effects of vegetation make the currents in saltmarsh fringes weaker and more complex.

Although wave breaking is the main driver of the current in a flooded saltmarsh fringe, it is not the only contributor. Astronomical tides and wind can also induce currents in tidal wetlands. The tidal range along the northern Gulf Coast is small and the wetlands are characterized as micro-tidal marshes (Stumpf and Haines 1998; Friedrichs and Perry 2001). Louisiana coast has tidal ranges varying from 0.1 to $0.2 \mathrm{~m}$ during neap tides to 0.3 to $0.6 \mathrm{~m}$ during spring tides (Leonard and Luther 1995). The tidal currents in micro-tidal wetlands are much smaller than the measured current velocity in this study. The tidal current velocity in the streamside of a marshland in Louisiana was less than $0.05 \mathrm{~m} / \mathrm{s}$, dropped to less than $0.03 \mathrm{~m} / \mathrm{s}$ for the interior marsh (Leonard and Luther 1995). In another study in Chesapeake Bay with a larger tidal range, flow velocity measured was $0.02 \sim 0.06 \mathrm{~m} /$ $\mathrm{s}$ adjacent to the canopy and $0.01 \sim 0.04 \mathrm{~m} / \mathrm{s}$ within the canopy (Leonard and Reed 2002). The much higher current velocity recorded in the marsh fringe in the present study suggests that wind waves rather than tides were the dominant driver of the current in the saltmarsh fringe under storm conditions.

Sea level rise, land subsidence, limited sediment supplies, wind wave impacts on the marsh boundaries and human activities are the main contributors to coastal wetland erosion (e.g., Ganju et al. 2013; Leonardi and Fagherazzi 2014). The northern Gulf Coast is subject to frequent, strong wind events due to cold front passages and tropical cyclones (e.g., Zhao and Chen 2008; Chen et al. 2008). As wind fetch increases due to the conversion of wetlands to open water, wave power impacting the perimeter of saltmarshes increases. Accelerated sea level rise along with land subsidence and reduced sediment supply that limits accretion, have increased wetland inundation frequency, and the inundation depth as elevations of the marsh surface decrease. Our field observations of waves and currents in a deteriorating saltmarsh fringe in Louisiana suggest that wind waves in marsh fringe zone can play a significant mechanism in the long-term stability and erosion of coastal wetlands under the conditions of accelerated sea level rise, subsidence, and reduction in sediment supplies. The field data also reveal the significance of vegetation submergence ratio. Although not investigated in this study, it can be deduced that taller and denser vegetation results in weaker currents and smaller wave orbital velocities in the wetland for a given inundation depth and offshore wave energy, because the vegetation drag is proportional to the stem height and vegetation density (e.g., Chen and Zhao 2012). However, vegetation density of saltmarshes depends on hydroperiod and flooding frequency, as lower elevations increase inundation depth. For instance, as inundation depth increases, stronger waves occur that generate undertows, or seaward currents on the surface of saltmarsh, which would promote the ebb flow of detritus on the marsh surface. This reduces the contribution of this organic matter to wetland accretion. Therefore, the conversion of coastal wetlands to open water in bays of deltaic environment may enhance the fetch that drives higher wave energy and increases the frequency of the undertow that erodes the surface of coastal wetlands. A restoration strategy that reduces wave energy with appropriately engineered systems and nourish the marshes with sediments simultaneously may be significant designs to allow saltmarshes to adapt to rising sea levels and subsidence.

\section{Conclusions}

A field experiment was carried out to study wind waves and flows in an inundated saltmarsh fringe zone during a storm passage in Terrebonne Bay, Louisiana. A bottom-mount pressure transducer was deployed $47 \mathrm{~m}$ seaward of the marsh edge and two acoustic Doppler velocimeters (ADVs) were deployed 1 and $2 \mathrm{~m}$ landward of the shore edge in the marsh fringe. A new deployment technique was developed to install 
and secure the ADVs during the storm on the weak soil of coastal wetlands, with minimal damage to the adjacent vegetation. This new technique allows for rapid installation of velocity sensors prior to a storm, which is useful for hurricanerelated field studies.

It was hypothesized that wave-driven currents dominate the flow in saltmarsh fringes under storm conditions. Based on the field data, relationships between the current velocity, current direction, and wave orbital velocity in the marsh fringe with the incident waves in the bay, local waves, inundation depth, vegetation submergence ratio, and vegetation density in the marsh fringe have been identified and quantified. Results show that the current velocity and wave orbital velocity in the marsh fringe were controlled by the incident waves, inundation depth, submergence ratio, and vegetation density (Figs. 9 and 10), which supports our hypothesis. The longshore and cross-shore currents in the marsh fringe correlated with the local wave energy, submergence ratio, and vegetation density inside the fringe zone. By introducing a dimensionless ratio of the current energy to the wave energy in the marsh fringe, it is shown that the current direction in the marsh fringe can be estimated by the wave energy, the submergence ratio and vegetation density in the saltmarsh fringe (Figs. 16). Further analyses of the velocity measurements have revealed the three-dimensional signature of the flow in the inundated saltmarsh fringe and the presence of an undertow in the velocity profile in the water column, which can negatively impact the health of coastal wetlands. It is worth noting that while these results show the dependency of the current in the marsh fringe on the incident and local waves, as well as on the inundation depth, submergence ratio, and vegetation density inside the fringe zone, it might not be the case for the internal marsh because the wave forcing is dissipated considerably by the vegetation as the distance from the marsh edge increases.

Although wind waves were a major driver of the currents in the saltmarsh fringe under storm conditions, tides and wind might also contribute to the observed flow. Our short-term deployment during the passage of a cold front system does not permit the separation of breaking-generated currents from tide-induced currents, but previous field studies showed much weaker currents in a micro-tidal wetland without waves than the measured current velocity in the present study. Obviously, more studies in other saltmarshes with higher platforms and different vegetation stem height or different population density as well as longer measurement duration are desirable to overcome the limitations of this field dataset. Although the single-point measurement of velocity by an ADV does not provide sufficient information about the vertical profile of the velocity in the marsh fringe, it provides the evidence for the presence of complex flow patterns. Future studies to resolve the vertical variation of currents in saltmarsh fringes are needed. Nevertheless, our field data show that the current and wave orbital velocities in the marsh fringe are the function of the inundation depth, submergence ratio, and vegetation density in the fringe zone and incident waves in the bay. Such a dataset will benefit the study of coastal wetland dynamics as well as the development and validation of three-dimensional models for waves and currents in saltmarsh wetlands in Louisiana and beyond.

\section{Notation}

$a_{v}$ Vegetation frontal area per canopy volume

$a_{1}, b_{1}$ Normalized Fourier coefficients

$C_{D}$ Drag coefficient

$C_{M}$ Inertia coefficient

$d_{p}$ Distance between the pressure sampling point and the bed $d_{u} \sim$ Distance between the velocity sampling point and the bed $d_{v}$ Vegetation stem diameter

$E_{w}$ Local wave energy on the marsh

$f$ Frequency

$F_{b}$ External body force

$F_{v}$ Vegetation force

$g$ Gravitational acceleration

$h$ Mean water depths on the marsh

$h_{i}$ Mean water depth in the bay

$h_{1}-h_{4}$ Mean water depths on the marsh at cross sections 1 to 4

$H_{b}$ Breaking wave height

$H_{m 0}$ Zero-moment wave height

$h_{s}$ Stem height

$h_{v}$ Vegetation height

$k$ Wave number

$K_{p}$ Dynamic pressure to the surface elevation conversion factor

$K_{\widetilde{u} \sim}$ Surface elevation to the horizontal orbital velocity conversion factor

$L_{i}$ Wavelength in the bay

$N_{v}$ Vegetation population density

$p$ Pressure

$R^{2}$ Coefficient of determination

$S_{p p}$ Wave dynamic pressure spectrum

$S_{\widetilde{u} \sim}$ Power spectrum for wave orbital velocity in the $x$ direction

$S_{\widetilde{v} \sim}$ Power spectrum for wave orbital velocity in the $y$ direction

$S_{\widetilde{u} \sim}$ Power spectrum for combined horizontal wave orbital velocity

$S_{\eta}$ Water surface elevation power spectral density

$S_{\tilde{\eta}}$ Water level and $x$ direction orbital velocity cross spectrum

$S_{\eta \widetilde{v}}$ Water level and $y$ direction orbital velocity cross spectrum

$t$ Time

$T_{i}$ Mean wave period in the bay

$T_{p}$ Peak wave period 
$u$ Velocity vector

$\bar{u}$ Time-averaged horizontal current velocity

$\bar{u}_{C S}$ Time-averaged cross-shore current velocity

$\bar{u}_{E}$ Time-averaged current velocity in the east direction

$\bar{u}_{L S}$ Time-averaged longshore current velocity

$\bar{u}_{N}$ Time-averaged current velocity in North direction

$\widetilde{u}$ Horizontal component of the wave orbital velocity in the $x$ direction

$\widetilde{u}_{m-\text { RMS }}$ Root mean square (RMS) of the maximum wave orbital velocity

$u_{10}$ Offshore wind velocity

$\widetilde{v}$ Horizontal component of the wave orbital velocity in the $y$ direction

$\bar{V}_{l}$ Longshore current velocity at the mid-surf zone

$\alpha_{b}$ Breaking wave angle

$\Delta s$ Spacing between homogeneously distributed plants

$\Delta x$ Spacing between plants in the $x$ direction

$\Delta y$ Spacing between plants in the $y$ direction

$\bar{\theta}_{c}$ Mean current direction

$\bar{\theta}_{w}$ Mean wave direction of an entire spectrum

$\theta_{1}$ Mean wave direction for each frequency

$\nu$ Kinematic viscosity of water

$\rho$ Water density

Acknowledgments The study was supported in part by the National Science Foundation (NSF Grant Nos. DMS-1115527 and SEES1427389) and the Louisiana Board of Regents. Ranjit Jadhav, Kyle Parker, Ling Zhu, and Qi Fan assisted in the field study. Any opinions, findings, conclusions and recommendations expressed in this paper are those of the authors and do not necessarily reflect the views of the NSF.

Open Access This article is distributed under the terms of the Creative Commons Attribution 4.0 International License (http://creativecommons.org/ licenses/by/4.0/), which permits unrestricted use, distribution, and reproduction in any medium, provided you give appropriate credit to the original author(s) and the source, provide a link to the Creative Commons license, and indicate if changes were made.

\section{References}

Anderson M., and J. Smith. 2014. Wave attenuation by flexible, idealized salt marsh vegetation. Coastal Engineering 83: 82-92.

Barrett-O'Leary, M. 2011. Functions and Values of Wetlands in Louisiana. Louisiana State University Agricultural Center, Publication \#2519.

Belcher S.E., N. Jerram, and J.C.R. Hunt. 2003. Adjustment of a turbulent boundary layer to a canopy of roughness elements. Journal of Fluid Mechanics 488: 369-398.

Blackmar P.J., D.T. Cox, and W.C. Wu. 2014. Laboratory observations and numerical simulations of wave height attenuation in heterogeneous vegetation. Journal of Waterway, Port, Coastal and Ocean Engineering 140(1): 56-65.

Boesch D.F., M.N. Josselyn, A.J. Mehta, J.T. Morris, W.K. Nuttle, C.A. Simenstad, et al. 1994. Scientific assessment of coastal wetland loss, restoration and management in Louisiana. Journal of Coastal Research 20: 1-103.
Callaghan D.P., T.J. Bouma, P. Klaassen, D. Van der Wal, M.J.F. Stive, and P.M.J. Herman. 2010. Hydrodynamic forcing on salt-marsh development: distinguishing the relative importance of waves and tidal flows. Estuarine, Coastal and Shelf Science 89(1): 73-88.

Chen Q., and H. Zhao. 2012. Theoretical models for wave energy dissipation caused by vegetation. Journal of Engineering Mechanics 138(2): 221-229. doi:10.1061/(ASCE)EM.1943-7889.0000318.

Chen Q., J.T. Kirby, R.A. Dalrymple, F. Shi, and E.B. Thornton. 2003. Boussinesq modeling of longshore currents. Journal of Geophysical Research 108(C11): 3362. doi:10.1029/2002JC001308.

Chen Q., L. Wang, and R. Tawes. 2008. Hydrodynamic response of northeastern gulf of Mexico to hurricanes. Estuaries and Coasts 31(6): 1098-1116. doi:10.1007/s12237-008-9089-9.

Costanza R., O. Pérez-Maqueo, M.L. Martinez, P. Sutton, S.J. Anderson, and K. Mulder. 2008. The value of coastal wetlands for hurricane protection. Ambio 37(4): 241-248.

Couvillion B.R., J.A. Barras, G.D. Steyer, W. Sleavin, M. Fischer, H. Beck, N. Trahan, B. Griffin, and D. Heckman. 2011. Land area change in coastal Louisiana (1932 to 2010). US Geological Survey: US Department of the Interior.

Dahl, T. E. 1990. Wetlands losses in the United States, 1780's to 1980's. Report to the Congress (No. PB-91-169284/XAB). National Wetlands Inventory, St. Petersburg, FL (USA).

Fagherazzi S., G. Maiotti, P.L. Wiberg, and K.J. McGlathery. 2013. Marsh collapse does not require sea level rise. Oceanography 26: 70-77.

Folkard A.M. 2011. Vegetated flows in their environmental context: a review. Proceedings of the ICE - Engineering and Computational Mechanics 164(1): 3-24.

Friedrichs C.T., and J.E. Perry. 2001. Tidal salt marsh morphodynamics: a synthesis. Journal of Coastal Research 27: 7-37.

Ganju N.K., N.J. Nidzieko, and M.L. Kirwan. 2013. Inferring tidal wetland stability from channel sediment fluxes: observations and a conceptual model. Journal of Geophysical Research: Earth Surface 118(4): 2045-2058.

Gourlay M.R. 1996. Wave set-up on coral reefs. 1. Set-up and wavegenerated flow on an idealised two dimensional horizontal reef. Coastal Engineering 27(3): 161-193.

Gourlay M.R., and G. Colleter. 2005. Wave-generated flow on coral reefs - an analysis for two-dimensional horizontal reef-tops with steep faces. Coastal Engineering 52(4): 353-387.

Gulf Restoration Network. 2004. A guide to protecting wetlands in the Gulf of Mexico. spring 2001 (updated spring 2004).

Hearn C.J. 1999. Wave-breaking hydrodynamics within coral reef systems and the effect of changing relative sea level. Journal of Geophysical Research, Oceans (1978-2012) 104(C12): 3000730019.

Hu K., Q. Chen, and H. Wang. 2015. A numerical study of vegetation impact on reducing storm surge by wetlands in a semi-enclosed estuary. Coastal Engineering 95: 66-76.

Jadhav R., and Q. Chen. 2013. Probability distribution of wave heights attenuated by salt marsh vegetation during tropical cyclone. Coastal Engineering 82: 47-55.

Jadhav R., Q. Chen, and J.M. Smith. 2013. Spectral distribution of wave energy dissipation by salt marsh vegetation. Coastal Engineering 77: 99-107.

Komar P.D. 1979. Beach-slope dependence of longshore currents. Journal of the Waterway, Port, Coastal and Ocean Division 105(4): 460-464.

Komar P.D., and D.L. Inman. 1970. Longshore sand transport on beaches. Journal of Geophysical Research 75(30): 5914-5927.

Lacy J.R., and D.J. Hoover. 2011. Wave exposure of Corte Madera marsh, 2011-1183. Marin County, California: A field investigation. U.S. Geological Survey Open-File Report. 
Lapetina A., and Y.P. Sheng. 2014. Three-dimensional modeling of storm surge and inundation including the effects of coastal vegetation. Estuaries and Coasts 37(4): 1028-1040.

Leonard L.A., and M.E. Luther. 1995. Flow hydrodynamics in tidal marsh canopies. Limnology and Oceanography 40(8): 1474-1484.

Leonard L.A., and D.J. Reed. 2002. Hydrodynamics and sediment transport through tidal marsh canopies. Journal of Coastal Research 36(2): 459-469.

Leonardi N., and S. Fagherazzi. 2014. How waves shape salt marshes. Geology 42(10): 887-890.

Longuet-Higgins M.S. 1970a. Longshore currents generated by obliquely incident sea waves: 1. Journal of Geophysical Research 75(33): 6778-6789.

Longuet-Higgins M.S. 1970b. Longshore currents generated by obliquely incident sea waves: 2. Journal of Geophysical Research 75(33): 6790-6801.

Louisiana Coastal Protection and Restoration Authority (CPRA). 2012. . http://www.coastalmasterplan.la.gov/

Luhar, M., Coutu, S., Infantes, E., Fox, S., and Nepf, H. 2010. Waveinduced velocities inside a model seagrass bed. Journal of Geophysical Research: Oceans (1978-2012), 115(C12).

Ma G., J.T. Kirby, S.F. Su, J. Figlus, and F. Shi. 2013. Numerical study of turbulence and wave damping induced by vegetation canopies. Coastal Engineering 80: 68-78.

Manca E., I. Caceres, J. Alsina, V. Stratigaki, I. Townend, and C.L. Amos. 2012. Wave energy and wave-induced flow reduction by full-scale model Posidonia oceanica seagrass. Continental Shelf Research 5051: $100-116$.

Marani M., A. d'Alpaos, S. Lanzoni, and M. Santalucia. 2011. Understanding and predicting wave erosion of marsh edges. Geophysical Research Letters 38(21).

Mariotti, G., and Fagherazzi, S. 2010. A numerical model for the coupled long-term evolution of salt marshes and tidal flats. Journal of Geophysical Research: Earth Surface (2003-2012), 115(F1).

Mariotti, G., Fagherazzi, S., Wiberg, P. L., McGlathery, K. J., Carniello, L., and Defina, A. 2010. Influence of storm surges and sea level on shallow tidal basin erosive processes. Journal of Geophysical Research: Oceans (1978-2012), 115(C11).

Marsooli R., and W. Wu. 2014. Numerical investigation of wave attenuation by vegetation using a 3D RANS model. Advances in Water Resources 74: 245-257.

McLoughlin S.M., P.L. Wiberg, I. Safak, and K.J. McGlathery. 2014. Rates and forcing of marsh edge erosion in a shallow coastal bay. Estuaries and Coasts 38: 620-638.

Möller I., M. Kudella, F. Rupprecht, T. Spencer, M. Paul, B.K. van Wesenbeeck, et al. 2014. Wave attenuation over coastal salt marshes under storm surge conditions. Nature Geoscience 7(10): 727-731.

Monismith S.G. 2007. Hydrodynamics of coral reefs. Annual Review of Fluid Mechanics 39: 37-55.

Montakhab, A., Yusuf, B., Ghazali, A. H., and Mohamed, T. A. 2012. Flow and sediment transport in vegetated waterways: a review. Reviews in Environmental Science and Bio/Technology 275-287.
Nepf H.M. 2012a. Flow and transport in regions with aquatic vegetation. Annual Review of Fluid Mechanics 44(1): 123-142.

Nepf H.M. 2012b. Hydrodynamics of vegetated channels. Journal of Hydraulic Research 50(3): 262-279.

Ozeren Y., D.G. Wren, and W. Wu. 2013. Experimental investigation of wave attenuation through model and live vegetation. Journal of Waterway, Port, Coastal, and Ocean Engineering. doi:10.1061/ (ASCE)WW.1943-5460.0000251.

Paul, M., and Amos, C. L. 2011. Spatial and seasonal variation in wave attenuation over Zostera noltii. Journal of Geophysical Research: Oceans (1978-2012), 116(C8).

Prahalad, V., Sharples, C., Kirkpatrick, J., \& Mount, R. 2014. Is windwave fetch exposure related to soft shoreline change in swellsheltered situations with low terrestrial sediment input? Journal of Coastal Conservation 1-11.

Stedman S.M., and T.E. Dahl. 2008. Status and trends of wetlands in the coastal watersheds of the eastern United States, 1998 to 2004. National Marine Fisheries Service: National Oceanic and Atmospheric Administration.

Stumpf R.P., and J.W. Haines. 1998. Variations in tidal level in the gulf of Mexico and implications for tidal wetlands. Estuarine, Coastal and Shelf Science 46(2): 165-173.

Symonds G., and K. Black. 2001. Predicting wave-driven currents on surfing reefs. Journal of Coastal Research 29: 102-114.

Symonds G., K.P. Black, and I.R. Young. 1995. Wave-driven flow over shallow reefs. Journal of Geophysical Research 100(C2): 26392648.

Tartinville, B., and Rancher, J. 2000. Wave-induced flow over Mururoa atoll reef. Journal of Coastal Research 16(3): 776-781.

Tibbetts J. 2006. Louisiana's wetlands: a lesson in nature appreciation. Environmental Health Perspectives 114(1): A40.

Tonelli, M., Fagherazzi, S., and Petti, M. 2010. Modeling wave impact on salt marsh boundaries. Journal of Geophysical Research: Oceans (1978-2012), 115(C9).

Truong, M. K., Whilden, K. A., Socolofsky, S. A., and Irish, J. L. 2014. Experimental study of wave dynamics in coastal wetlands. Environmental Fluid Mechanics 1-30.

Wamsley T.V., M.A. Cialone, J.M. Smith, J.H. Atkinson, and J.D. Rosati. 2010. The potential of wetlands in reducing storm surge. Ocean Engineering 37(1): 59-68.

Wang F.C., T. Lu, and W.B. Sikora. 1993. Intertidal marsh suspended sediment transport processes, Terrebonne bay, Louisiana, USA. Journal of Coastal Research 9(1): 209-220.

Wiberg P.L., and C.R. Sherwood. 2008. Calculating wave-generated bottom orbital velocities from surface-wave parameters. Computers \& Geosciences 34(10): 1243-1262.

Zhao H., and Q. Chen. 2008. Characteristics of extreme meteorological forcing and water levels in mobile bay, Alabama. Estuaries and Coasts 31(4): 704-718. doi:10.1007/s12237-008-9062-7.

Zhao H., and Q. Chen. 2014. Modeling attenuation of storm surge over deformable vegetation: methodology and verification. Journal of Engineering Mechanics 140(12): 04014090. 